\title{
Molecular Modeling of Coprocessing Biomass Fast Pyrolysis Oil in Fluid Catalytic Cracking Unit
}

DOI:

10.1021/acs.iecr.9b05361

\section{Document Version}

Accepted author manuscript

Link to publication record in Manchester Research Explorer

\section{Citation for published version (APA):}

Al Jamri, M. Y. M. E., Li, J., \& Smith, R. (2020). Molecular Modeling of Coprocessing Biomass Fast Pyrolysis Oil in Fluid Catalytic Cracking Unit. Industrial \& Engineering Chemistry Research, 59(5), 1989-2004.

https://doi.org/10.1021/acs.iecr.9b05361

\section{Published in:}

Industrial \& Engineering Chemistry Research

\section{Citing this paper}

Please note that where the full-text provided on Manchester Research Explorer is the Author Accepted Manuscript or Proof version this may differ from the final Published version. If citing, it is advised that you check and use the publisher's definitive version.

\section{General rights}

Copyright and moral rights for the publications made accessible in the Research Explorer are retained by the authors and/or other copyright owners and it is a condition of accessing publications that users recognise and abide by the legal requirements associated with these rights.

\section{Takedown policy}

If you believe that this document breaches copyright please refer to the University of Manchester's Takedown Procedures [http://man.ac.uk/04Y6Bo] or contact uml.scholarlycommunications@manchester.ac.uk providing relevant details, so we can investigate your claim.

\section{OPEN ACCESS}




\title{
Molecular Modelling of Co-processing Biomass
}

\section{Fast Pyrolysis Oil in Fluid Catalytic Cracking Unit}

\author{
Mohamed Al Jamri, Jie Li ${ }^{*}$, Robin Smith \\ Centre for Process Integration \\ Department of Chemical Engineering and Analytical Science
}

The University of Manchester

Manchester M13 9PL United Kingdom

Keywords: Catalytic cracking, Fast pyrolysis oil, biomass, molecular modelling, Molecular Type and Homologous Series (MTHS) Matrix

* Corresponding author (E-mail: jie.li-2@ manchester.ac.uk) 


\section{ABSTRACT}

Integration of renewable sources into transportation fuels production system through FCC units in an oil refinery has gained increased attention. For better understanding of the effect of reaction conditions, blending ratios and feed properties on product yields and qualities, kinetic modelling of FCC units is necessarily required. In this paper, a novel framework for molecular-level modelling of co-processing biomass pyrolysis oil with VGO in an oil refinery FCC unit is developed, which includes molecular-level characterisation of biomass pyrolysis oil and VGO feed blends, synthesis of large-scale and complex reaction network, molecularlevel kinetic modelling and parameter estimation. The rule "same type of reactions has similar activation energies" is employed to significantly reduce the number of kinetic parameters. The kinetic parameters in the proposed model are estimated using a hybrid solution algorithm combining deterministic and stochastic optimisation methods. The computational results demonstrate an overall good agreement between measured and predicted yields using the developed kinetic model for VGO: FPO blending ratio, $\mathrm{C} / \mathrm{O}$ ratio and reaction temperature of 95:5, 5 and $530{ }^{\circ} \mathrm{C}$, respectively. PONA composition in each layer of product stream (e.g. gasoline, diesel, gasoil, etc.) as well as oxygen compounds compositions and oxygen content are also successfully predicted. The proposed framework can be easily to be extended for modelling of other refinery processes and creates potentials for rigorous simulation and optimisation of refinery operations in order to achieve maximisation of refinery profit or better product quality control. 


\section{Introduction}

Integration of renewable sources into transportation fuels production system has gained increased attention over the last few decades. ${ }^{1}$ One of the potential integration points where biomass-based fast pyrolysis oil (FPO) is first mixed together with petroleum gas oil (VGO) and then co-processed in oil refinery fluidised catalytic cracking units. ${ }^{2}$ Numerous efforts have investigated the feasibility and viability of co-processing pyrolysis liquids in oil refinery hydroprocessing units, ${ }^{3-6}$ as well as oil refinery FCC units. ${ }^{7-11}$ The effects of co-processing pyrolysis oil with other refinery intermediate on product yields and quality were investigated. It is concluded that oil refinery FCC process arises as a suitable candidate for co-processing biomass pyrolysis oil with petroleum gasoil fractions (atmospheric and vacuum gasoil) mainly due to the ability of FCC units in handling a wide range of different feedstocks with different boiling ranges and properties. In addition, FCC catalysts are known to be tolerant to oxygenates, water, carbon monoxide, and carbon dioxide, ${ }^{12}$ which is superior to other processes with oxygenates-sensitive catalysts. Extensive experimental research has been carried out on co-processing biomass pyrolysis liquids with gas oil fractions in FCC units. ${ }^{13,14}$ A number of these efforts tries to look over the promising aspects of co-processing bio oil in FCC units. ${ }^{15-18}$ This is done by identifying the effects of reaction conditions and blending ratios on products' yields and quality. ${ }^{8,} 17$ More recently, model compounds are used in several experimental studies in order to develop an understanding of reaction pathways and reaction network for bio oil components on the surface of FCC catalysts. ${ }^{12,19}$

To develop better understanding of the effect of reaction conditions, blending ratios and feed properties on product yields and qualities, kinetic modelling of FCC units is necessarily required. There are three types of kinetic models available to describe the catalytic cracking kinetics in an oil refinery FCC process ${ }^{20}$ including correlation-based approaches, mechanistic approaches, and lumping modelling approaches. Correlation-based approaches use properties 
and composition of feedstock to analyse their effects on products' distribution. ${ }^{21}$ However, other factors such as reaction temperature, catalyst to oil ratio, and feed velocity in FCC riser cannot be quantified. ${ }^{20}$ Mechanistic models use the knowledge of carbonium ion chemistry for synthesis of detailed catalytic cracking reaction network. ${ }^{22}$ The main limitation of this approach is that extensive computational power and time are required for the synthesis of reaction network and generation of lumping coefficient. ${ }^{22}$ Lumps modelling approach is based on lumping feed and product components according to bulk properties and boiling ranges. Since it is simple to set up and could provide a reasonably accurate prediction of product distribution, it is often used to simplify modelling and simulation of the oil refinery FCC unit.

The earliest work using lumping techniques was done by Blanding. ${ }^{23}$ Only two lumps were used for modelling of catalytic cracking of heavy oil. Following the work of Blanding, ${ }^{23}$ a 3-lump model was developed by Weekman and Nace. ${ }^{24}$ The main advantage of this 3-lump model over the previous 2-lump model is its ability to predict gasoil and gasoline yield simultaneously. However, this model suffers from the dependency of estimated kinetic parameters on feedstock. Extensive work is done on kinetic modelling using lumped approach with various numbers of lumps (up to 34 lumps). A comprehensive reference of these works can be found in Naik et al. ${ }^{12}$ The main advantages of lumping modelling approach are its simplicity in set up and ability to provide a reasonably accurate prediction of product distribution. In addition, using lumping modelling approach, kinetic parameters can be easily estimated. ${ }^{12}$ However, the main disadvantage of this approach is the fact that the results obtained using this type of models are usually case-dependent, i.e. different set of kinetic parameters are required for each feedstock. Further, compositional changes of different molecular attributes within a single lump cannot be captured using lumping modelling techniques, which may affect the understanding of the kinetics of the process. ${ }^{20}$ 
To overcome the shortcomings of the previously mentioned modelling approaches, Gomez-Prado ${ }^{25}$ developed a 32-lump model to represent and retain structural information of the various structural attributes found in each cut of catalytic cracking feedstock and product spectrum. This in turn helps reduce the dependency of kinetic parameters on feedstock compositions. In addition, kinetic behaviour of the various molecular attributes is better captured and represented. However, relatively large deviation (i.e., 12.6\%) is found between predicted product distribution and plant data. This model is further enhanced through integration of a molecular-level characterisation method based on Molecular Type and Homologous Series (MTHS) Matrix framework and detailed molecular-level reaction network. $^{20}$ The major deviation between experimental and predicted product distribution is significantly reduced. The integrated characterisation-process modelling approach developed by Gomez-Prado ${ }^{25}$ is very similar to that proposed by $\mathrm{Hu}$ et $\mathrm{al}^{26}$ In the work of $\mathrm{Hu}$ et al., ${ }^{26}$ they proposed a general framework that can be used to optimise refinery operation via molecular management concept implementation. The work was further extended by $\mathrm{Zhu}^{27}$ to develop a systematic methodology for process synthesis based on molecular-level analysis of process streams. Several case studies illustrate the added value of implementing the proposed methodology for process synthesis and optimisation. The aforementioned efforts, although demonstrated feasibility and viability of implementation of molecular management concept for refinery operational optimisation and process synthesis, none of which considered the integration of new type of feedstocks with completely different molecules such as those found in biomass pyrolysis oil.

Very few efforts have been made on kinetic modelling of co-processing biomass pyrolysis oil with VGO in fluid catalytic cracking units. Naik et al. ${ }^{12}$ proposed a 5-lump kinetic model for the modelling of catalytic cracking of Jatropha Curcas seed cake-derived fast pyrolysis oil on the surface of equilibrium catalyst (E-CAT) in advanced cracking 
evaluation (ACE-R) FCC unit. Cruz et al. ${ }^{28}$ developed a model for co-processing hydrodeoxygenated pyrolysis oil (HDO-oil) with VGO in an oil refinery FCC unit. The model comprises 10 real components and 40 pseudo-components. A probabilistic approach is used to define a large reaction network with more than 12,000 reaction terms. The main limitation of these two models is their inability to accurately characterise feedstock and product stream based on molecular size and structure simultaneously. The change in structural composition within a single lump cannot be captured in the kinetics. As a result, true kinetics of catalytic cracking reactions might be masked.

To overcome the limitations of the aforementioned models, a novel framework for molecular-level modelling of co-processing biomass pyrolysis oil with VGO in an oil refinery FCC unit is developed in this work. In the framework, the previously developed MTHS matrix framework is first extended for molecular-level characterisation of biomass pyrolysis oil and gasoil blends. ${ }^{2}$ Then a rigorous reaction network is constructed and a detailed kinetic model which takes into account the complex interactions between the various molecular attributes present in the feed stream on the surface of cracking catalyst is developed. The rule "same type of reactions has similar activation energies" from Gomez-Prado ${ }^{20}$ is employed to significantly reduce the number of kinetic parameters. The kinetic parameters in the proposed model are estimated via a hybrid solution algorithm combining deterministic and stochastic optimisation approaches. The developed framework is evaluated using experimental data obtained from Naik et al. ${ }^{12,14}$ for co-processing biomass fast pyrolysis oil (FPO) in lab-scale Micro Activity Testing (MAT) unit. The computational results demonstrate a good agreement between experimental data and model predictions.

\section{Molecular Modelling Framework}

The proposed Framework for molecular-level modelling of co-processing biomass pyrolysis oil with VGO in an oil refinery FCC unit mainly consists of three steps. First, the feedstock 
which is a bio oil and VGO blend to the FCC unit is characterized using Molecular Type and Homologous Series (MTHS) matrix approach proposed in the work of Al Jamri et al. ${ }^{2}$ Second, molecular-level reaction network in FCC units is synthesized based on the existing information in the literature and molecular modelling of the synthesized reaction network is carried out. Finally, the kinetic parameters are estimated using parameter estimation approach. A solution approach combining stochastic optimisation algorithm (Genetic Algorithm) and deterministic optimisation method (Sequential Quadratic Programming) is developed to solve the parameter estimation problem and generate optimal values for the kinetic parameters.

\subsection{Feedstock Characterisation}

The feedstock to FCC unit is characterised using the extended MTHS matrix characterisation approach of Al Jamri et al. ${ }^{2}$ as illustrated in Figure 1. In this approach, an extended 2-D MTHS matrix is first used to capture the size and structure of the molecules present in the feedstock simultaneously. While previously defined homologous series used for petroleum fractions representation are reserved for characterisation of VGO composition in the feedstock, new homologous series to represent oxygenated molecules in the bio oil is added in the matrix. Then, the compositional matrix is obtained by solving an optimisation problem in which the objective function is to minimise the difference between measured and predicted bulk properties and structural information. The resulting matrix comprises petroleum-based hydrocarbon molecules, as well as bio-based oxygenated homologous series representing bio oil fraction in the blended stream. The resulting MTHS matrix could provide detailed molecular-level information of the feedstock for kinetic modelling. Thorough description of the characterisation approach adopted can be referred to Al Jamri et al. ${ }^{2}$

\subsection{Reaction Network Synthesis}

Detailed molecular-level modelling of catalytic cracking reaction network is not a trivial task. The complexity of this task increases significantly when biomass pyrolysis oil is introduced in 
the feed stream of catalytic cracking unit. This is mainly because of the limited literature available on reaction pathways for bio oil molecules. In addition, the already known kinetic behaviour of conventional petroleum fraction in catalytic cracking units may be affected when biomass pyrolysis oil is blended with the feed stream. For this reason, a molecular-level reaction network, which takes into account the complex interactions between various molecules and catalyst surface is devised for the modelling of catalytic cracking reactors.

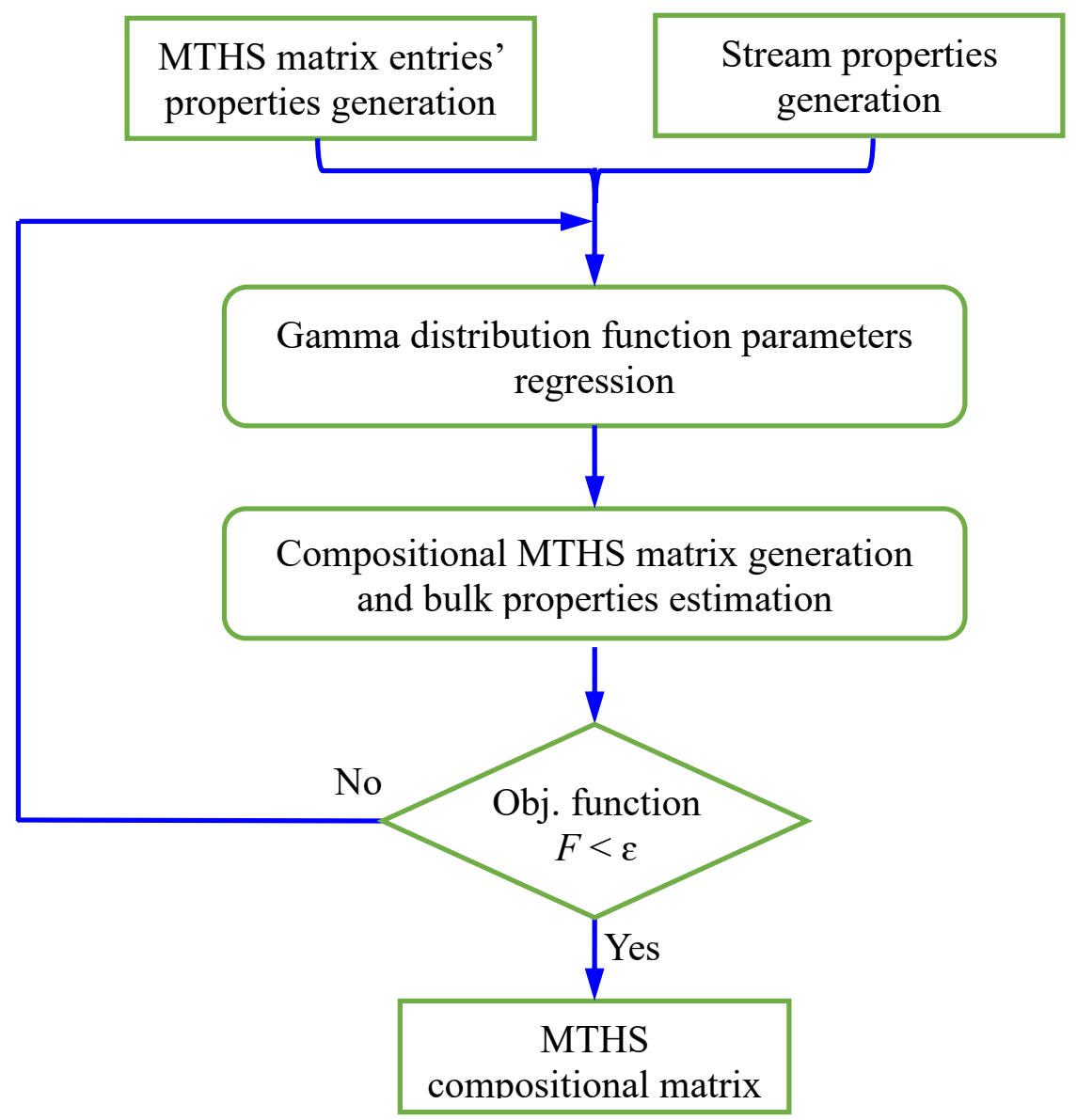

Figure 1 MTHS matrix solution algorithm

\subsubsection{Hydrocarbon Reaction Network}

Reaction pathways for catalytic cracking of hydrocarbon molecules are readily available in literature. ${ }^{29,30}$ The main requirement for the synthesis of molecular-level reaction network is the ability to discriminate between molecules based on molecular structure and size, hence capturing the difference in reaction pathways, as well as reaction kinetics. In this work, 
hydrocarbon reaction network is adopted from Gomez-Prado ${ }^{20}$ in which 299 reaction terms are used to describe the behaviour of 20 lumped species consisting of four structural attributes, i.e. paraffins, aromatics, naphthenes, and olefins (PONA) by five boiling levels and 11 real components. Out of these 299 terms, 25 reactions are used to describe catalytic cracking reactions of light gases $\left(\mathrm{C}_{1}\right.$ to $\left.\mathrm{C}_{4}\right)$. Reaction terms for paraffins, aromatics, naphthenes, and olefins at each boiling cut are determined from Watson et al..$^{31-35}$ and Gates. ${ }^{36}$ The reaction network for paraffins homologous series across the various product cuts is shown in Figure 2. The interconversion between the various levels and structures of the molecules is demonstrated.

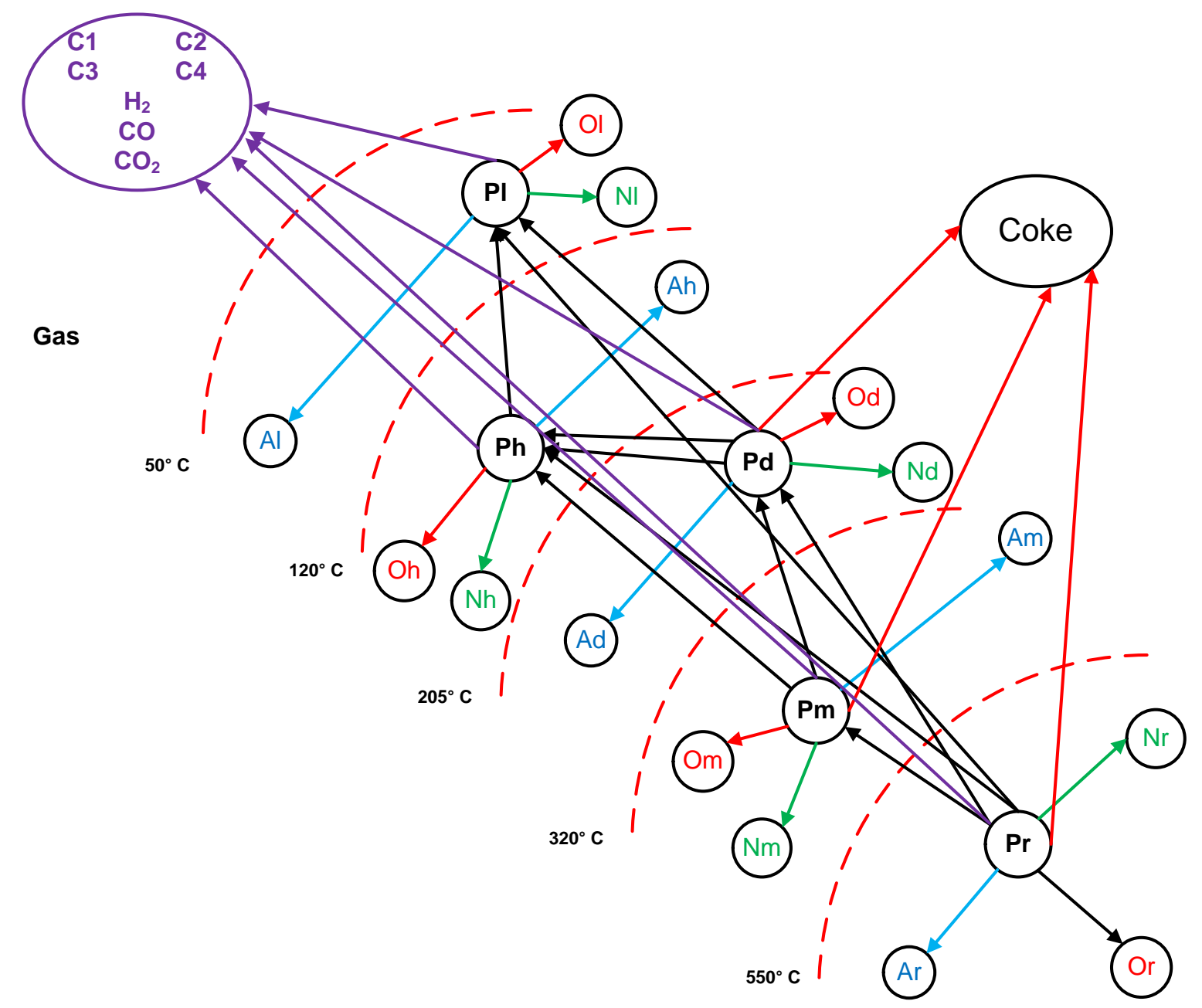

Figure 2 Reaction network for paraffin homologous series (P: paraffin, O: olefins, N: naphthene, A: aromatic, r: residue cut, m: gasoil cut, d: diesel cut, h: heavy gasoline cut, l: 
light gasoline cut)

\subsubsection{Oxygenates Reaction Network}

Biomass pyrolysis oil homologous series are lumped into 4 groups in order to synthesise reaction network according to functional oxygen atoms: acids and esters, phenolics, aldehydes and ketones, and alcohols. Since the available information on oxygenates catalytic cracking reaction pathways and kinetic data is scarce, reaction rules for bio molecules are deduced from studies of bio oil model compounds catalytic cracking. ${ }^{37-39}$ Adjaye and Bakhshi ${ }^{38}$ used representative model compounds to propose reaction networks and pathways for the various types of oxygenates found in bio oil. Representative compounds were selected based on their abundance in their respective chemical groups in typical bio oil mixtures. Catalytic cracking reactions of model compounds were performed on HZSM-5 catalyst in a fixed-bed microreactor at weight hourly space velocity (WHSV) of 3.6 and atmospheric pressure. Conversions at different temperatures were measured to validate the proposed reaction network by performing kinetic studies. ${ }^{37}$

\section{Organic Acids and Esters}

Adjaye and Bakhshi ${ }^{38}$ studied the conversion of propanoic acid and methyl ester of acetic acid over HZSM-5. Catalytic cracking reaction network was postulated for organic acids and esters. Both species were given similar treatment due to the fact that reactivity of organic acids and their esters derivatives are similar. The proposed reaction network is shown in Figure 3. According to the mechanism shown in Figure 3, acid and ester species in bio oil catalytic cracking process go through parallel reaction routes.

The first route involves decarboxylation of organic acid to produce $\mathrm{CO}_{2}$ and paraffinic hydrocarbons. The second route is deoxygenation of organic acids and esters with subsequent production of aldehydes and ketones through aldol condensation reactions. ${ }^{40}$ It is reported that oxygen rejection of organic acids and esters occurs mainly through decarboxylation and 
deoxygenation to produce $\mathrm{CO}_{2}$ and water, respectively. ${ }^{40,}{ }^{41}$ Using the proposed reaction scheme, the following reaction rules are proposed for catalytic cracking of organic acid and esters homologous series in the MTHS matrix:

$\operatorname{Acid} \& \operatorname{Esters}(n) \rightarrow P(n-1)+\mathrm{CO}_{2}$

where $n$ is the boiling level of the homologous series within the feedstock matrix. Acid \& Esters ( $n$ ) denotes lump of acid and esters at boiling level $n$, and $P(n)$ denotes paraffin lumps at boiling level $n$.

For light fractions acids and esters (heavy gasoline range and lighter), the reaction rules are:

Acid \& Esters $\rightarrow$ light gases $+\mathrm{CO}_{2}$

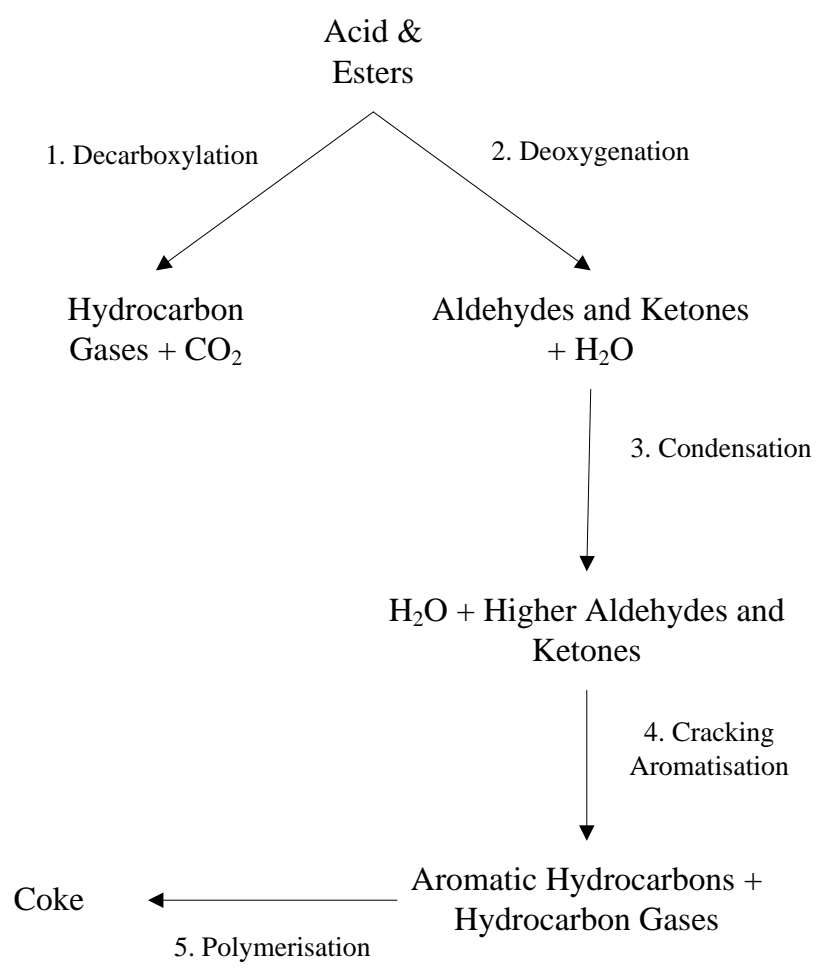

Figure 3 Reaction pathway for the conversion of acids and esters (Adapted from Adjaye and Bakhshi $^{38}$ )

\section{Phenolics}

Phenols and substituted phenols are one of the most important types of oxygenates in bio oil due to the large abundance of phenolic compounds in bio oil fractions, as well as the 
difficulty of phenolic oxygen group removal in catalytic cracking reactions. ${ }^{37,38}$ The reaction of phenol was studied over FCC catalyst to postulate a representative reaction network for phenolics homologous series in the MTHS matrix. Phenolic oxygen removal from phenols in catalytic cracking reactions occurs via dehydration and subsequent production of aromatics ${ }^{42}$, ${ }^{43}$ as shown in Figure 4.

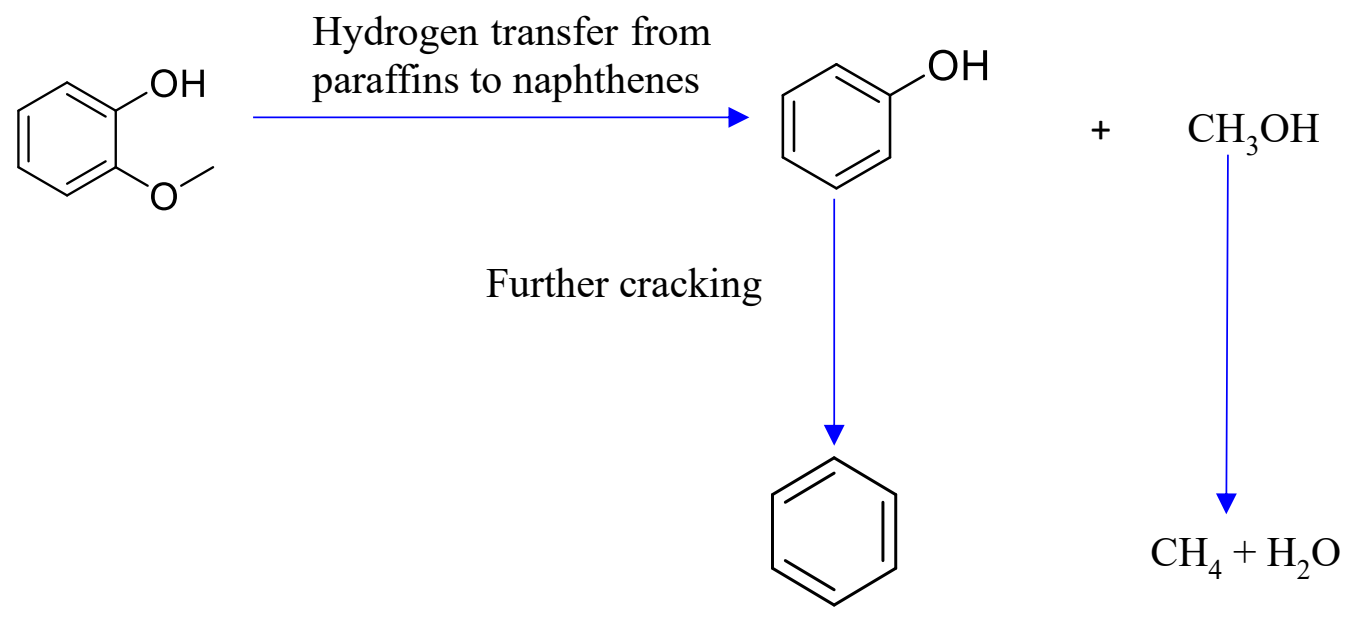

Figure 4 Probable mechanism of cracking of guaiacol with VGO

Adjaye and Bakhshi ${ }^{38}$ also investigated catalytic cracking reactions of substituted phenols. Figure 5 shows their proposed reaction scheme. The reaction of substituted phenols over zeolite catalysts was found to occur largely via molecules isomerisation. ${ }^{38,40,44}$ In addition, to a much lower extent, substituted phenols can go through alkyl group cracking or addition to produce light gases or alkylated phenols. At a similar rate, condensation reactions of substituted phenols produce coke and water. ${ }^{38}$

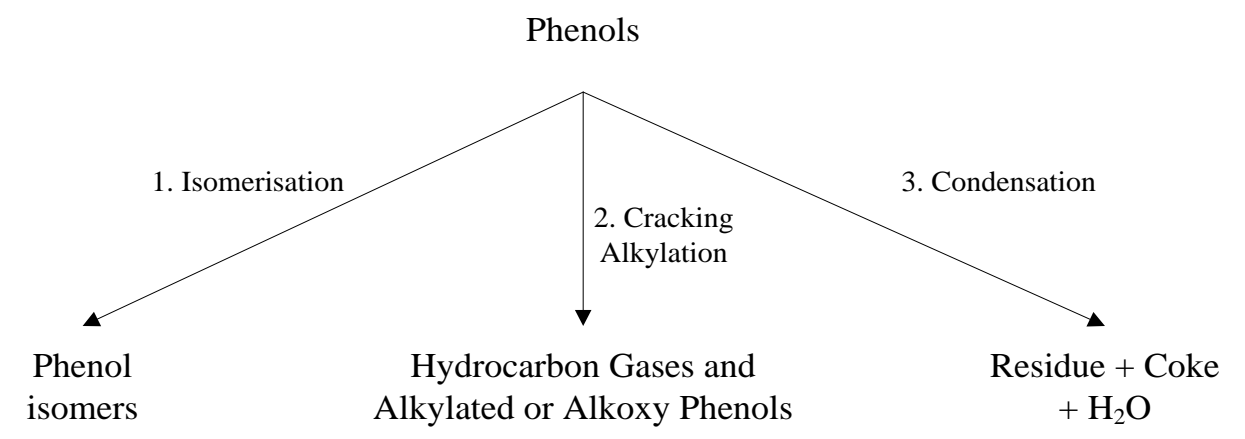

Figure 5 Reaction pathway for the conversion of Phenols (adapted from Adjaye and 


\section{Bakhshi $\left.^{38}\right)$}

In this work, phenolic oxygen removal via dehydration is considered to be the major mechanism of catalytic cracking of phenolics homologous series in the MTHS matrix. Isomerisation reactions are not considered mainly because isomerisation does not change the total composition of phenolics lumps in a given product cut. Therefore, this isomerisation reaction is masked by definition of the characterisation method used. The following reactions rules are defined for catalytic cracking reactions of phenolics homologous series:

$$
\begin{aligned}
& \text { Phe }(n-1)+\mathrm{H}_{2} \rightarrow \mathrm{A}(n)+\mathrm{H}_{2} \mathrm{O} \\
& \text { Phe }(n)+\mathrm{H}_{2} \rightarrow \text { Coke }+\mathrm{H}_{2} \mathrm{O}
\end{aligned}
$$

where Phe $(n)$ is phenolics homologous series in boiling level $n$ within feedstock matrix, and $A(n)$ denotes aromatics lump at boiling level $n$.

For light fractions ( $\leq$ light gasoline):

$$
\operatorname{Phe}(n)+\mathrm{H}_{2} \rightarrow \mathrm{A}(\mathrm{n})+\mathrm{H}_{2} \mathrm{O}
$$

Aldehydes and Ketones

Adjaye and Bakhshi ${ }^{38}$ studied catalytic cracking of cyclopentanone and 2methylcyclopentanone (2-MCP) over HZSM-5 catalyst to investigate reaction network and kinetics of aldehydes and ketones catalytic cracking. The proposed reaction network is shown in Figure 6. They suggested that catalytic deoxygenation (step 1) and decarbonylation (step 5) are the main routes of oxygen group removal in catalytic cracking of aldehydes and ketones. 


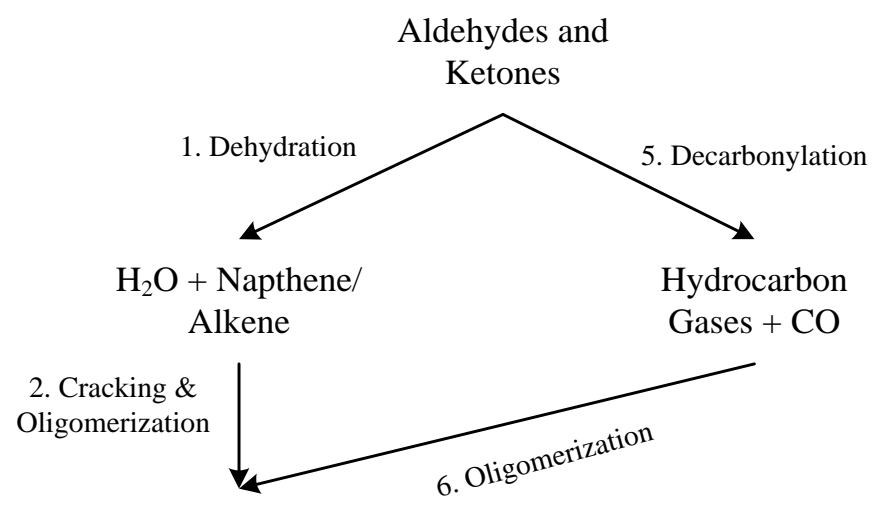

Olefins

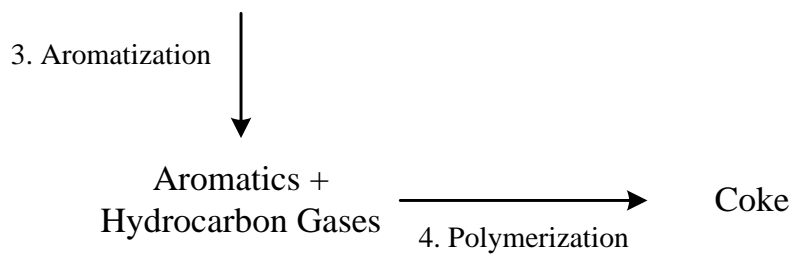

Figure 6 Reaction pathway for the conversion of aldehydes and ketones (adapted from Adjaye and Bakhshi ${ }^{38}$ )

The first route suggests that the molecules go through dehydration reaction to produce water and alkene (naphthene in the case of cyclic molecule). The olefin produced then goes through aromatisation reaction to produce aromatic hydrocarbons, hydrocarbon gases, and coke. The second route involves decarbonylation of cyclic ketone molecule to produce carbon monoxide and hydrocarbon gases. The gases can go through oligomerisation reactions to produce olefins. Due to the fact that cyclic aldehydes and ketones are not considered in the characterisation framework used, deoxygenation of aldehydes and ketones groups is considered to take place via dehydration only in this work. The following reaction rule is proposed for the modelling of catalytic cracking reactions of aldehydes and ketones fractions in the MTHS matrix characterisation framework:

Ald and $\mathrm{Ket}(n)+\mathrm{H}_{2} \rightarrow \mathrm{O}(n-1)+\mathrm{H}_{2} \mathrm{O}$

where Ald and $\operatorname{Ket}(n)$ is aldehydes and ketones homologous series in boiling level $n$ within the feedstock's matrix and $O(n)$ is olefins homologous series in boiling level $n$. 


\section{Alcohols}

Adjaye and Bakhshi ${ }^{38}$ observed that catalytic cracking of 4-methylcyclohexnol over HZSM-5 involves dehydration to produce water and naphthene (or alkene in the case of linear alcohol). Figure 7 shows the proposed reaction network for alcohol fraction of bio oil. Step 1-3 (Figure 7) are reported to be the main reaction route for alcohol cracking over FCC catalyst, ${ }^{38,40}$ which is the same main reaction route as reported by Chen et al. ${ }^{40}$ The second reaction route suggests the formation of light hydrocarbon gases, carbon monoxide, and smaller size linear alcohol via ring opening mechanism.

In this work, alcohol homologous series in the MTHS matrix characterisation framework is assumed to be linear only. Therefore, only alcohol dehydration route is considered for the reaction network. The following reaction rule is used for the modelling of alcohols catalytic cracking reactions:

$$
\operatorname{Alcohol}(n) \rightarrow O(n-1)+\mathrm{H}_{2} \mathrm{O}
$$

Where $\operatorname{Alcohol}(n)$ is alcohol homologous series in boiling leveln.

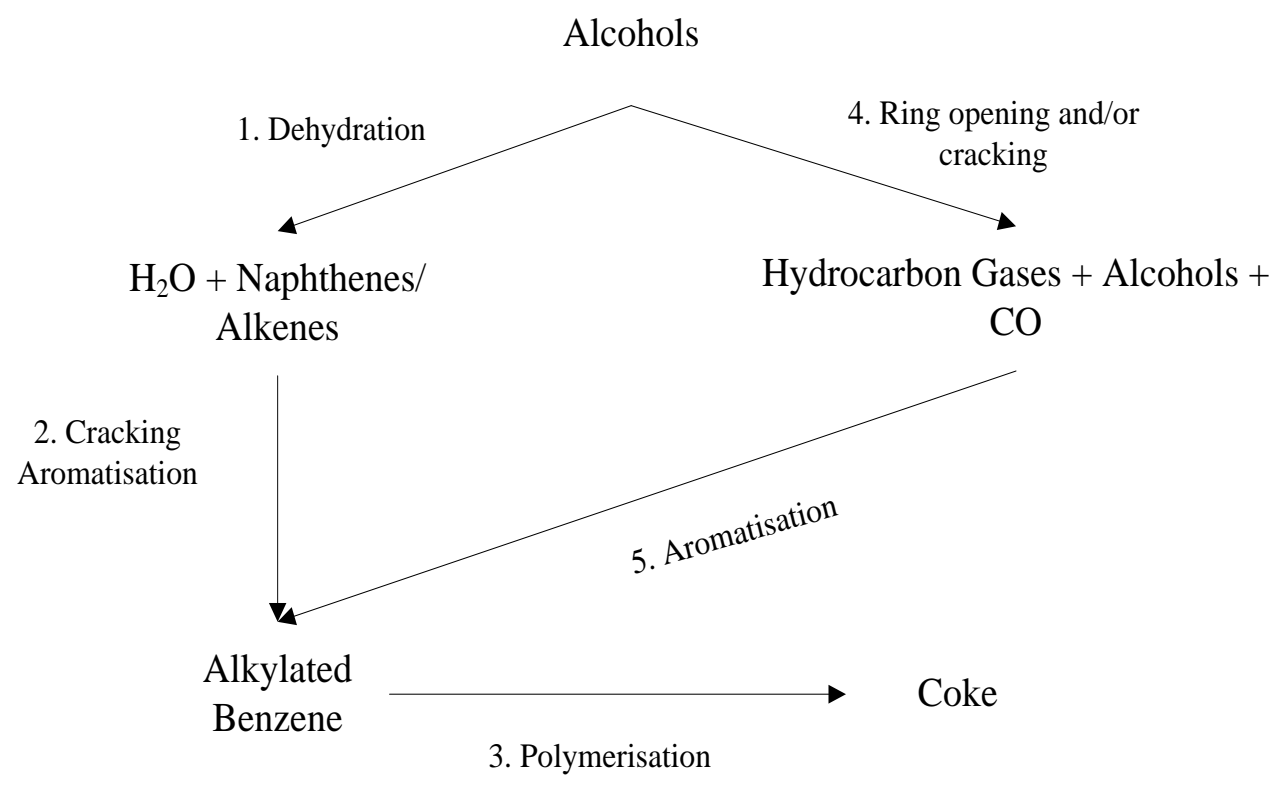

Figure 7 Proposed reaction pathways for the conversion of alcohols (adapted from Adjaye and Bakhshi ${ }^{38}$ ) 


\subsection{Kinetic Expression}

Selection of rate expression type in kinetic modelling is of high importance. The type of rate expression used in any reaction model determines model suitability for simulation and optimisation at different operating conditions. For example, Langmuir-Hinshelwood-HougenWatson (LHHW) rate expression can be used to account for equilibrium and competitive adsorption in aromatics hydrogenation reactions. ${ }^{45}$ Therefore, a given reaction model based on LHHW rate expression can accommodate variations of temperature and pressure simultaneously. However, such LHHW rate expression is not preferred to be used in this work due to the complexity of the proposed reaction network and difficulties in solving kinetic parameters estimation problem. Therefore, a simple Arrhenius type rate expression with two kinetic parameters, namely activation energy $\left(E a_{i}\right)$ and pre-exponential factor $\left(k 0_{i}\right)$ is used to develop the kinetic model for the proposed catalytic cracking kinetic network.

$$
k_{s}=k 0_{s} \exp \left(-\frac{E a_{s}}{R T}\right) \quad \forall s
$$

where $s$ is set of reactions defined in the reaction network. The initial values of kinetic parameters are adopted from Gomez-Prado ${ }^{20}$ and Adjaye and Bakhshi ${ }^{37}$ for hydrocarbon and oxygenates reactions, respectively. The values of the activation energies are then modified using a regression strategy as explained in section 2.5. In the regression/optimisation problem, the initial values of activation energies as well as lower and upper bounds were selected based on the values reported in Gomez-Prado ${ }^{20}$ and Adjaye and Bakhshi. ${ }^{37}$ The values of the preexponential factor are obtained from the literature were left untouched. It should be noted that activation energy is identified using the rule "Same type of reactions has similar activation energies", ${ }^{20}$ which significantly reduces the number of kinetic parameters to be estimated. 


\subsection{Reactor Model Development}

A plug-flow reactor (PFR) is assumed in this work for modelling of a fixed-bed Advanced Cracking Evaluation (ACE-R) FCC unit due to small amount of catalyst used and uniform profiles of temperature, pressure and liquid flow maintained in the small-scale fixed-bed reactor. Reaction temperature and pressure are carefully controlled at $530{ }^{\circ} \mathrm{C}$ and 1 bar, respectively. Adiabatic steady-state operation with no pressure gradient in the reactor is assumed. Complete wetting of catalyst particles and absence of radial concentration profiles were also assumed, which further strengthens the assumption of plug-flow behaviour in the reactor. ${ }^{46}$ The PFR model is formulated and solved against conversion rates of the blended feedstock as follows:

$$
\begin{array}{ll}
\frac{d C_{i}}{d x}=\varphi \cdot \rho_{c a t} \cdot \sum_{j} r_{j i} C_{i}^{\alpha} & \forall i \\
r_{j i}=a_{j i} k 0_{j i} \exp \left(-\frac{E a_{j i}}{R T}\right) & \forall i, j
\end{array}
$$

where $C_{i}$ is concentration of lump $i, \alpha$ is the order of the reaction, $x$ is conversion of feedstock, $\rho_{c a t}$ is catalyst density, $r_{j i}$ denotes reaction rate of lump $i$ to lump $j, a_{j i}$ is stoichiometric coefficient of reaction between lump $i$ and lump $j, k 0_{j i}$ is Arrhenius preexponential factor of reaction between lumps $j$ and $i, E a_{j i}$ is activation energy, $R$ and $T$ are universal gas constant and reaction temperature, respectively. $\varphi$ is catalyst deactivation function. Selection of catalyst deactivation function is extremely important for the modelling of FCC unit. Generally, deactivation functions are empirical. In other words, they are different for each type of feedstock due to the effect of the relative influence of site coverage and pore plugging on catalyst deactivation. ${ }^{47}$ Different forms of catalyst deactivation functions are available in literature. ${ }^{47-49}$ In this work, catalyst deactivation function proposed by Pitault et al. ${ }^{47}$ is employed because it provides best fit for experimental data: 


$$
\varphi=\frac{B+1}{B+\exp (A \cdot c)}
$$

where $A$ and $B$ are empirical constants and $c$ is catalyst carbon content (wt.\%).

\subsection{Kinetic Parameters Estimation}

Kinetic parameters in the proposed kinetic model are estimated through solving an optimisation problem whose objective is to minimise the difference between measured and model-predicted values of product yields and properties, reaction temperatures, etc. In this work, yields of products including dry gas, LPG, gasoline, LCO, and HCO are used to validate model-predicted results. The parameter estimation problem is formulated as a nonlinear programming (NLP) problem below, which is denoted as $\mathbf{P}$.

(P) $\quad \min \quad z=\sum_{L, k} W_{L} \sqrt{\left(Y_{L, k}^{m s d}-Y_{L, k}^{P R E}\right)^{2}}+\sum_{k=1}^{4}\left(x_{k}^{m s d}-x_{k}^{P R E}\right)^{2}$

$$
\begin{aligned}
& \text { s.t. } \operatorname{WHSV}(k)=4 \times 1 \\
& \forall k=1,2,3,4 \\
& \text { Xspan }=[0: 0.001: x(k)] \\
& \forall k=1,2,3,4 \\
& M_{F}(k)=m_{c a t} \cdot W H S V(k) \\
& \forall k=1,2,3,4 \\
& V_{F}(k)=\frac{M_{F}(k)}{\rho_{F}(k)} \\
& \forall k=1,2,3,4 \\
& m_{F}(L, k)=M_{F}(k) \cdot X_{w t}(L) \\
& \forall k, L \\
& n_{F}(L, k)=\frac{M_{F}(k)}{M W(L)} \\
& \forall k, L \\
& C_{0}(L, k)=\frac{n_{F}(L, k)}{V_{F}(k)} \\
& \forall k, L \\
& \frac{d C(L, k)}{d x}=\varphi \cdot \rho_{c a t} \cdot \sum_{j} r_{j L} C_{L} \quad \forall k, L \\
& r_{j L}=a_{j L} \cdot k_{0_{j L}} \cdot \exp \left(-\frac{E_{a_{j L}}}{R T}\right) \quad \forall j, L
\end{aligned}
$$




$$
\begin{array}{ll}
M_{P}(L, k)=V_{F}(k) \cdot C(L, k) \cdot M W(L) & \forall j, L \\
\operatorname{yield}(L, k)=\frac{M_{P}(L, k)}{\sum_{L^{\prime}} M_{P}\left(L^{\prime}, k\right)} & \forall k, L
\end{array}
$$

where $z$ denotes the objective function; $Y$ denotes measured product yield (dry gas, LPG, gasoline, LCO, and HCO) (wt.\%); WHSV is weight hourly space velocity of liquid feed in the reactor $\left(\mathrm{h}^{-1}\right) ; x$ is conversion of blended feedstock; $\dot{M}_{F}$ is feed stream mass flowrate; $m_{c a t}$ is catalyst mass in reactor; $\dot{V}_{F}$ is the volume flowrate of feed stream; $\rho_{F}$ is feed density; $m_{F}$ is 58 $\times 1$ vector of flowrate of 58 components (lumps) comprising feedstock stream; $X_{w t}(L)$ is weight composition of lump $L$ in feedstock stream. $n_{F}(L)$ is molar flowrate of lump $L$ in feed stream; $M W(L)$ is molecular weight of lump $L . C(L)$ denotes molar concentration of lump $L$; $\dot{M}_{P}(L)$ is mass flowrate of lump $L$ in product stream P. msd and PRE denote measured and model-predicted values; set $i$ denotes experimental data. here four data sets. Different types of objective function may be used in kinetic tuning problems. Usually, however, relative or absolute differences are used to minimise the difference between measured and model predicted yields. In this work, absolute difference between measured and model-predicted yields and conversions is used in the objective function. Due to relative differences in the magnitude of absolute differences computed for each product fraction, weights are used to give the same size for each difference included in the objective function.

The optimisation problem has 14 continuous variables, 12 of which are activation energies for 12 reaction families used to define the developed reaction network. The developed reaction network contains 328 reactions. This means that a large number of reactions share the same activation energy. The use of the concept of reaction families significantly reduced the number of variables in this optimisation problem. The two remaining regression variables are those associated with catalyst deactivation function $(\varphi)$. 
The proposed model $\mathbf{P}$ contains a number of nonlinear ordinary differential equations (ODEs). The nonlinearity is essentially introduced by exponential reaction rate terms. This type of NLP model $\mathbf{P}$ can be solved using deterministic (derivative-based) ${ }^{50-53}$ and stochastic (derivative-free) ${ }^{52,54}$ methods. While deterministic methods often guarantee solution quality especially for convex nonlinear problems, stochastic methods such as Genetic Algorithm (GA) often finds a good feasible initial point for the parameter estimation problem with less computational efforts. ${ }^{55}$ To utilize the advantages of both methods, hybrid optimisation algorithms for parameters estimation were proposed recently, ${ }^{56,57}$ which combined the stochastic algorithm such as Simulated Annealing (SA) with the deterministic method such as Successive Quadratic Programming (SQP).

In this work, a hybrid optimisation algorithm which is similar to that of Bekirogullari et al. ${ }^{56}$ is used for kinetic parameters estimation in which a stochastic method GA is used to obtain a good feasible initial solution. Since GA can generate different starting points for searching, it has better opportunity to obtain a feasible solution in the vicinity of global optimum. Then a deterministic method SQP is used to improve the quality of the feasible solution obtained by GA. GA often involves four fundamental steps: Generation of random population, Evaluation of fitness function (fitness of individuals), Selection of best individuals, and Reproduction of solution (offspring) using numerical genetic operator (mutation and crossover). These steps represent a single iteration in the GA solution procedure. The four steps mentioned above are repeated until some termination criteria is satisfied. Termination criteria used in this work are maximum number of generation or population convergence. The best feasible solution is obtained from the individual with the best performance in the last generation. This hybrid algorithm does not necessarily require an initial starting point. In addition, the use of the SQP method in the hybrid algorithm does increase the numerical robustness with very high reproducibility of the results obtained. The 
hybrid algorithm is illustrated in Figure 8.

\section{Case Study}

Experimental data from Naik et al. ${ }^{12,14}$ are used to evaluate the proposed modelling framework for molecular-level kinetic modelling of co-processing biomass fast pyrolysis oil (FPO) with VGO in an oil refinery FCC unit. Properties of biomass pyrolysis oil, VGO and the feedstock blend are given in Table 1-2. Catalytic cracking experiments are carried out in an ACE-R FCC unit. The experimental studies were performed using commercially available VGO and equilibrium fluid catalytic cracking catalyst. The experiments were carried out by varying the weight hourly space velocity (WHSV) between $6 \mathrm{~h}^{-1}$ and $24 \mathrm{~h}^{-1}$. Catalyst to oil ratio $(\mathrm{C} / \mathrm{O})$ and reaction temperature were kept constant at 5 and $530{ }^{\circ} \mathrm{C}$, respectively. Product stream was characterised using boiling ranges: dry gas $\left(\mathrm{H}_{2}, \mathrm{C}_{1}-\mathrm{C}_{2}\right.$ hydrocarbons), LPG (C3$\mathrm{C} 4$ hydrocarbons), gasoline $\left(\mathrm{C} 5-216{ }^{\circ} \mathrm{C}\right)$, light cycle oil (LCO) $\left(216{ }^{\circ} \mathrm{C}-370{ }^{\circ} \mathrm{C}\right)$, heavy cycle oil $(\mathrm{HCO})\left(>370{ }^{\circ} \mathrm{C}\right)$, and coke. A summary of experimental setup and conditions is presented in Table 3. Detailed description of experimental setup including catalyst characterisation, reactor setup and reaction conditions, and feedstock properties could be found in Naik et al. ${ }^{12,14}$ 


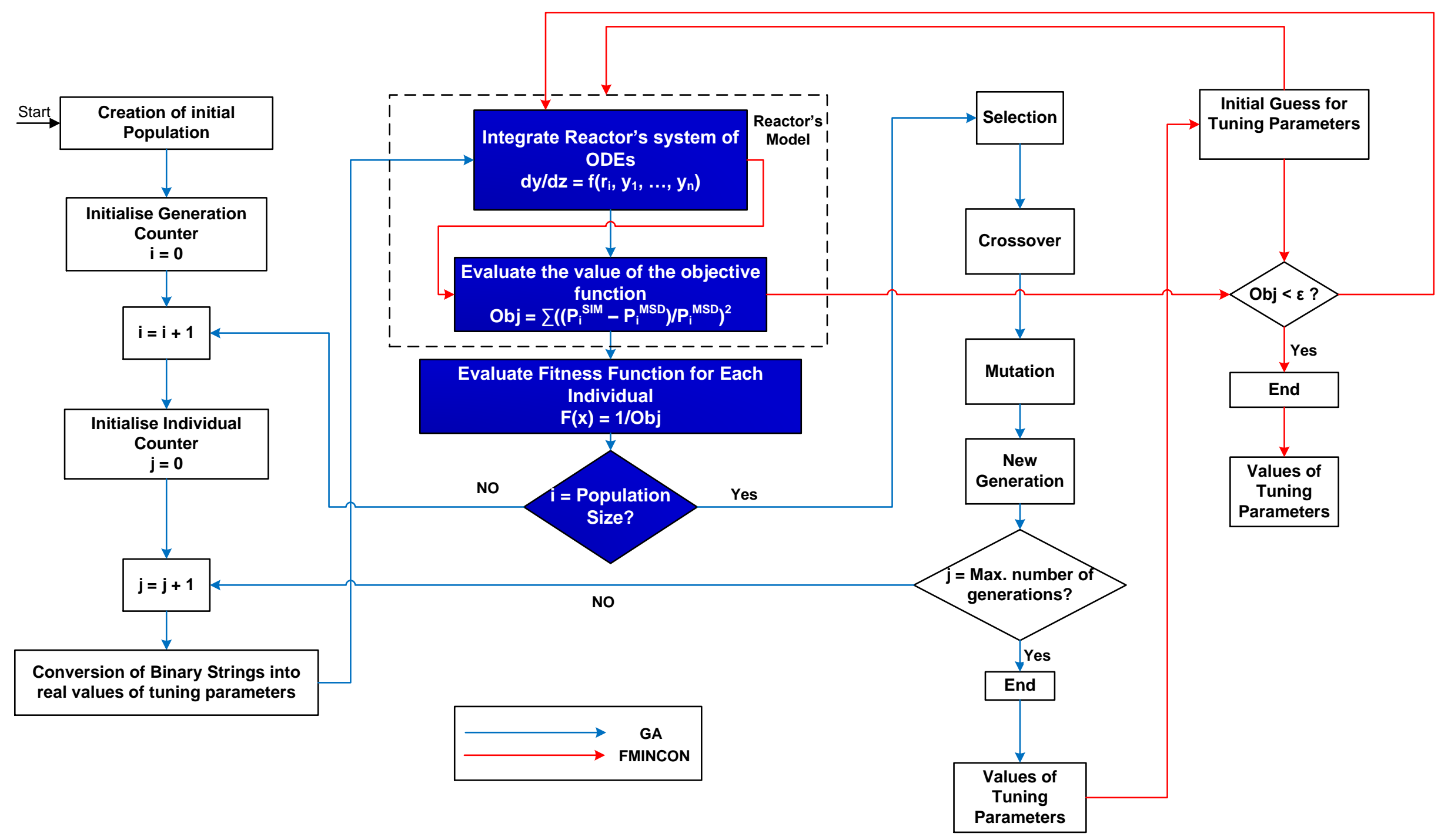

Figure 8 Proposed hybrid algorithm for kinetic parameter estimation 
Table 1 Properties of VGO and FPO feedstocks ${ }^{14}$

\begin{tabular}{|c|c|c|c|c|c|c|c|c|c|}
\hline \multirow[b]{3}{*}{ Feedstock } & \multirow{3}{*}{$\begin{array}{l}\text { Density } \\
\left(\mathrm{kg} \mathrm{m}^{-3}\right)\end{array}$} & \multirow[b]{3}{*}{ CCR, wt.\% } & \multicolumn{7}{|c|}{ Simulated Distillation Data, ${ }^{\circ} \mathrm{C}$} \\
\hline & & & \multicolumn{7}{|c|}{ Mass Recovery, wt.\% } \\
\hline & & & IBP & $10 \%$ & $30 \%$ & $50 \%$ & $70 \%$ & $90 \%$ & FBP \\
\hline $\mathrm{VGO}$ & 0.919 & 3.64 & 350 & 369 & 400 & 441 & 489 & 550 & 550 \\
\hline FPO & 1.18 & 16.26 & 36 & 162 & 259 & 328 & 357 & 445 & 592 \\
\hline
\end{tabular}

Table 2 Properties of Feedstock Blend*

\begin{tabular}{|c|c|c|c|}
\hline Properties & Measured & Predicted & Relative Error (\%) \\
\hline Density $\left(\mathrm{kg} \mathrm{m}^{-3}\right)$ & 932.00 & 852.05 & -8.58 \\
\hline Total naphthene (wt.\%) & 54.78 & 55.06 & 0.52 \\
\hline Total aromatics (wt.\%) & 20.62 & 20.67 & 0.27 \\
\hline Total Paraffins (wt.\%) & 19.61 & 19.61 & 0.01 \\
\hline Oxygen Content (wt.\%) & 1.60 & 1.60 & -0.06 \\
\hline \multicolumn{4}{|l|}{ TBP Curve $\left({ }^{\circ} \mathrm{C}\right)^{\eta}$} \\
\hline $5 \mathrm{Vol} \%$ & 185.62 & 200.96 & 8.26 \\
\hline $20 \mathrm{Vol} \%$ & 392.34 & 395.20 & 0.73 \\
\hline $30 \mathrm{Vol} \%$ & 410.40 & 403.58 & -1.66 \\
\hline $50 \mathrm{Vol} \%$ & 453.57 & 434.14 & -4.28 \\
\hline $60 \mathrm{Vol} \%$ & 476.46 & 475.64 & -0.17 \\
\hline $70 \mathrm{Vol} \%$ & 500.98 & 514.19 & 2.64 \\
\hline $80 \mathrm{Vol} \%$ & 528.26 & 535.09 & 1.29 \\
\hline $90 \mathrm{Vol} \%$ & 554.11 & 544.61 & -1.71 \\
\hline $95 \mathrm{Vol} \%$ & 566.83 & 557.00 & -1.74 \\
\hline $100 \mathrm{Vol} \%$ & 579.69 & 587.07 & 1.27 \\
\hline
\end{tabular}


Table 3 Reactor configuration and operating conditions ${ }^{12,14}$

\begin{tabular}{ll}
\hline Reactor type & ACE-R \\
\hline $\mathrm{C} / \mathrm{O}$ & 5 \\
\hline Catalyst characteristics & \\
\hline Pore diameter $(\mathrm{nm})$ & 5 \\
\hline Specific surface area $\left(\mathrm{m}^{2} / \mathrm{g}\right)$ & 243 \\
\hline Operating conditions & \\
\hline Temperature $\left({ }^{\circ} \mathrm{C}\right)$ & 530 \\
\hline Pressure $($ bar $)$ & 1 \\
\hline WHSV $\left(\mathrm{h}^{-1}\right)$ & $6,8,12,24$ \\
\hline
\end{tabular}

\subsection{Feed Characterisation}

The feed stream is characterised using the molecular characterisation approach in Al jamri et al. ${ }^{2}$ The compositional MTHS matrix obtained with total composition of each structural group in each boiling level in the feed stream is presented in Table 4. Table 2 shows a comparison between measured and predicted properties and compositional information obtained.

Table 4 Predicted composition of blended feed stream*

\begin{tabular}{lllllll}
\hline & Light gas & $\begin{array}{l}\text { Light } \\
\text { gasoline }\end{array}$ & $\begin{array}{l}\text { Heavy } \\
\text { Gasoline }\end{array}$ & Diesel & Gasoil & Residues \\
\hline $\mathrm{P}$ & $7.67 \mathrm{E}-01$ & $2.59 \mathrm{E}-02$ & $7.01 \mathrm{E}-01$ & $6.09 \mathrm{E}+00$ & $2.99 \mathrm{E}+01$ & $1.83 \mathrm{E}+01$ \\
$\mathrm{O}$ & $0.00 \mathrm{E}+00$ & $0.00 \mathrm{E}+00$ & $1.85 \mathrm{E}-05$ & $4.48 \mathrm{E}-03$ & $1.74 \mathrm{E}-01$ & $1.80 \mathrm{E}-01$ \\
$\mathrm{~N}$ & $0.00 \mathrm{E}+00$ & $0.00 \mathrm{E}+00$ & $0.00 \mathrm{E}+00$ & $0.00 \mathrm{E}+00$ & $8.66 \mathrm{E}+00$ & $1.20 \mathrm{E}+01$ \\
A & $0.00 \mathrm{E}+00$ & $0.00 \mathrm{E}+00$ & $0.00 \mathrm{E}+00$ & $0.00 \mathrm{E}+00$ & $1.96 \mathrm{E}+01$ & $1.49 \mathrm{E}-02$ \\
Phenolic & $0.00 \mathrm{E}+00$ & $3.19 \mathrm{E}-01$ & $3.76 \mathrm{E}-01$ & $1.02 \mathrm{E}-01$ & $3.33 \mathrm{E}-02$ & $6.49 \mathrm{E}-02$ \\
Acid \& Es & $0.00 \mathrm{E}+00$ & $1.18 \mathrm{E}+00$ & $8.38 \mathrm{E}-01$ & $5.37 \mathrm{E}-02$ & $8.91 \mathrm{E}-04$ & $1.24 \mathrm{E}-06$ \\
Ald \& Ket & $0.00 \mathrm{E}+00$ & $5.26 \mathrm{E}-01$ & $1.75 \mathrm{E}-02$ & $2.66 \mathrm{E}-04$ & $6.64 \mathrm{E}-07$ & $0.00 \mathrm{E}+00$ \\
\hline
\end{tabular}




\begin{tabular}{lllllll}
\hline Alcohols & $0.00 \mathrm{E}+00$ & $1.77 \mathrm{E}-02$ & $3.13 \mathrm{E}-04$ & $4.07 \mathrm{E}-06$ & $0.00 \mathrm{E}+00$ & $0.00 \mathrm{E}+00$ \\
\hline
\end{tabular}

* VGO:FPO = 95:5 (mass basis). Es: Ester, Ald: Aldehydes, Ket: Ketones

As seen from Table 2, a maximum error of $8.58 \%$ was found in density prediction due to the error induced in the characterisation matrix calculation from the linear correlations used to estimate the density of oxygenates entries in the MTHS matrix model. ${ }^{2}$ Most relative errors between the measured and predicted values are smaller than 5\%, which is acceptable.

\subsection{Kinetic Parameters Estimation}

The compositional matrix obtained from feed characterisation is fed into the reaction network model. The parameters in the reaction network model are estimated using the hybrid optimisation algorithm, which is implemented in MATLAB 2016b with GA and SQP solvers. The settings for the GA and SQP solvers are given in Table 5.

Table 5 Settings of the hybrid solution algorithm

\section{Genetic algorithm}

\begin{tabular}{ll}
\hline Parameter & Value \\
Population size & 300 \\
Maximum generation & 400 \\
Fitness tolerance & $1.00 \mathrm{E}-06$ \\
Crossover fraction & 0.7 \\
Crossover function & 'intermediate' \\
Mutation function & 'adaptive feasible' \\
Fitness Scaling function & 'rank' \\
Selection function & 'tournament'
\end{tabular}

\section{FMINCON solver}

\begin{tabular}{ll}
\hline Algorithm & 'SQP' \\
Maximum function evaluation & 1000 \\
Step tolerance & $1.00 \mathrm{E}-15$ \\
\hline
\end{tabular}


Figure 5 clearly shows that the hybrid optimisation algorithm significantly improves solution quality and accuracy. For instance, the objective function (i.e., the difference between measured and predicated values) is reduced from 15.80 using GA only to 8.70 using the hybrid algorithm. The index of correlation $\left(\mathrm{R}^{2}\right)$ improves from 0.943 using GA only to 0.985 using the hybrid approach. To examine the stability of the hybrid solution algorithm, the model is solved in multiple times. The results are presented in Table 6. The values obtained for index of correlation $\left(\mathrm{R}^{2}\right)$ are all higher than 0.96 . The difference between the smallest and largest R2 values is 0.022 which is very small indicating not only stable solution algorithm, but also high accuracy of the solutions obtained.

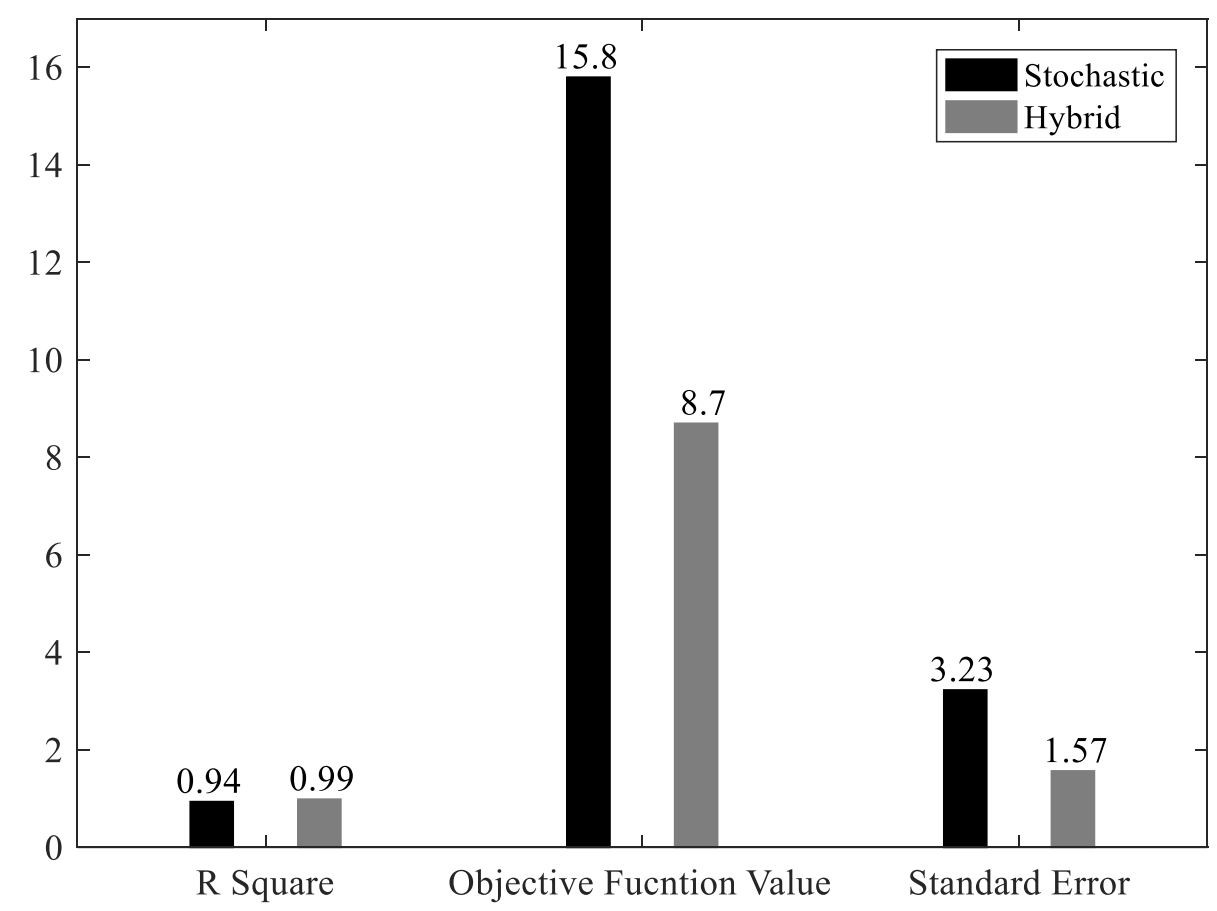

Figure 5 Comparative results obtained using GA and the hybrid algorithm

Table 6 Objective function and $\mathrm{R}^{2}$ values for multiple runs using the hybrid algorithm

\begin{tabular}{llllllll}
\hline Run number & 1 & 2 & 3 & 4 & 5 & 6 & 7 \\
\hline Objective function & 11.346 & 12.569 & 10.660 & 8.910 & 8.510 & 10.250 & 9.563 \\
$\mathrm{R}^{2}$ & 0.972 & 0.963 & 0.979 & 0.985 & 0.985 & 0.979 & 0.980 \\
\hline
\end{tabular}


Due to the nature of the stochastic part of the hybrid solution algorithm, each regression run is likely to land in a different solution space. To compensate for this deficiency, the regression model was run multiple times. The best results obtained are shown in Table 7 . Table 7 shows a comparison between measured and model-predicted values with different WHSV. Figure 6 shows experimental and predicted yields with different WHSV. The value of $\mathrm{R}^{2}$ is 0.985 , indicating good accuracy of fitting parameters obtained. This is also illustrated in Figure 7. Note that the values of the fitting parameters obtained are not unique, i.e. different set of values may give similar accuracy.

Table 7 Comparison between predicted and measured yields with different WHSV

\begin{tabular}{lcccccccc}
\hline WHSV $\left(\mathrm{h}^{-1}\right)$ & \multicolumn{3}{c}{6} & \multicolumn{3}{c}{8} & \multicolumn{3}{c}{12} & \multicolumn{2}{c}{24} \\
\hline \multirow{2}{*}{ Dry Gas } & Pred. & Exp. & Pred. & Exp. & Pred. & Exp. & Pred. & Exp. \\
\cline { 2 - 9 } LPG & 1.47 & 2.54 & 1.46 & 2.21 & 1.43 & 2.06 & 1.40 & 1.87 \\
Gasoline & 38.40 & 39.91 & 37.60 & 39.47 & 35.34 & 34.50 & 33.27 & 30.05 \\
LCO & 29.26 & 30.73 & 29.22 & 29.48 & 29.03 & 28.22 & 28.75 & 27.48 \\
HCO & 15.59 & 12.59 & 16.09 & 15.11 & 17.52 & 18.80 & 18.84 & 22.77 \\
Coke & 9.26 & 8.14 & 9.71 & 8.17 & 11.04 & 11.13 & 12.35 & 12.84 \\
& 6.02 & 6.08 & 5.92 & 5.56 & 5.65 & 5.29 & 5.39 & 4.99 \\
\hline
\end{tabular}

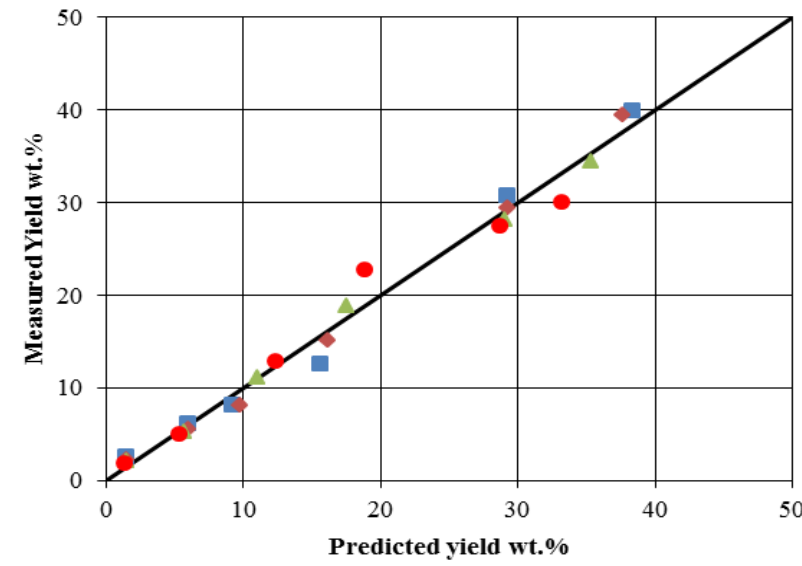

CWHSV $=6$

$\bullet$ WHSV $=8$

$\triangle \mathrm{WHSV}=12$

-WHSV $=24$

Figure 6 Parity plot of model-predicted and measured yields with different WHSV 


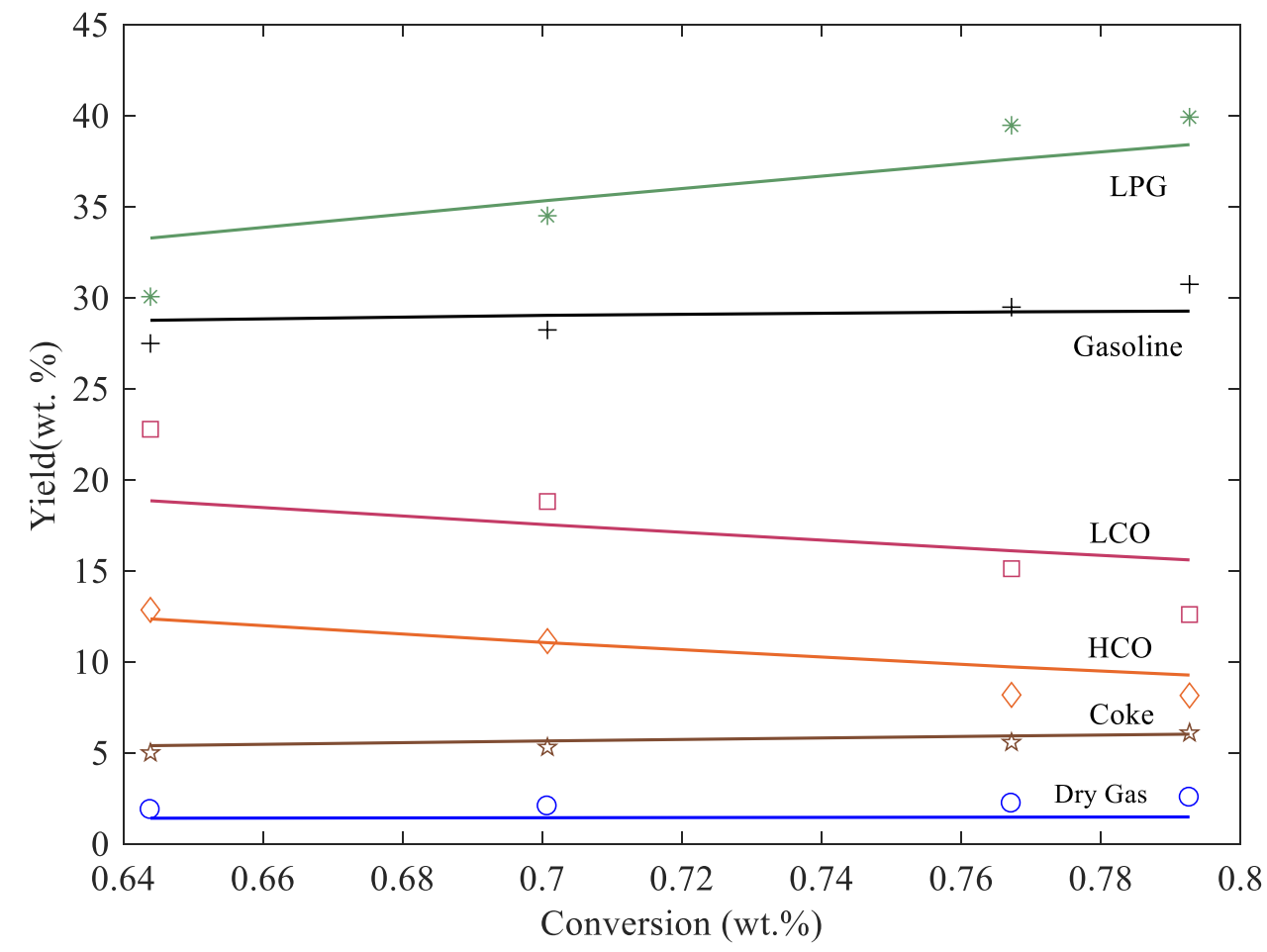

Figure 7 Comparison of product yields between predicted values and experimental data

\subsection{Product distribution}

Figure 8 and

Figure 9 show individual product yields as a function of conversion and WHSV, respectively. It can clearly be seen that as conversion increases, yields of cracking products (i.e., dry gas, LPG, and gasoline) increase, while yields of gas oil fractions (i.e., LCO and HCO) decrease. The main reason is that conversion increases with decreasing velocity (WHSV). Decreasing WHSV results in a larger contact time in the reactor, resulting in larger yields of lighter products. Typically, FCC units are operated to maximise gasoline yield in refinery operations. Therefore, operation in gasoline over-cracking region is avoided. ${ }^{58-62}$

\subsection{PONA Compositions in Liquid Products}

The main benefit of using molecular-level modelling framework is the ability to predict the composition of a structural group in each product. Figure 10 shows PONA composition in liquid products including light gasoline (LG), heavy gasoline (HG), diesel (DS), gasoil (GO), and residue (Res). This feature of the proposed modelling framework not only helps in 
monitoring and optimising the composition and quality of each product fraction, it also helps in applying molecular management concepts to FCC unit, one of the most important refinery processes. In other words, it helps in sending the right molecule to the right product fraction at the right time and prices. ${ }^{63,64}$

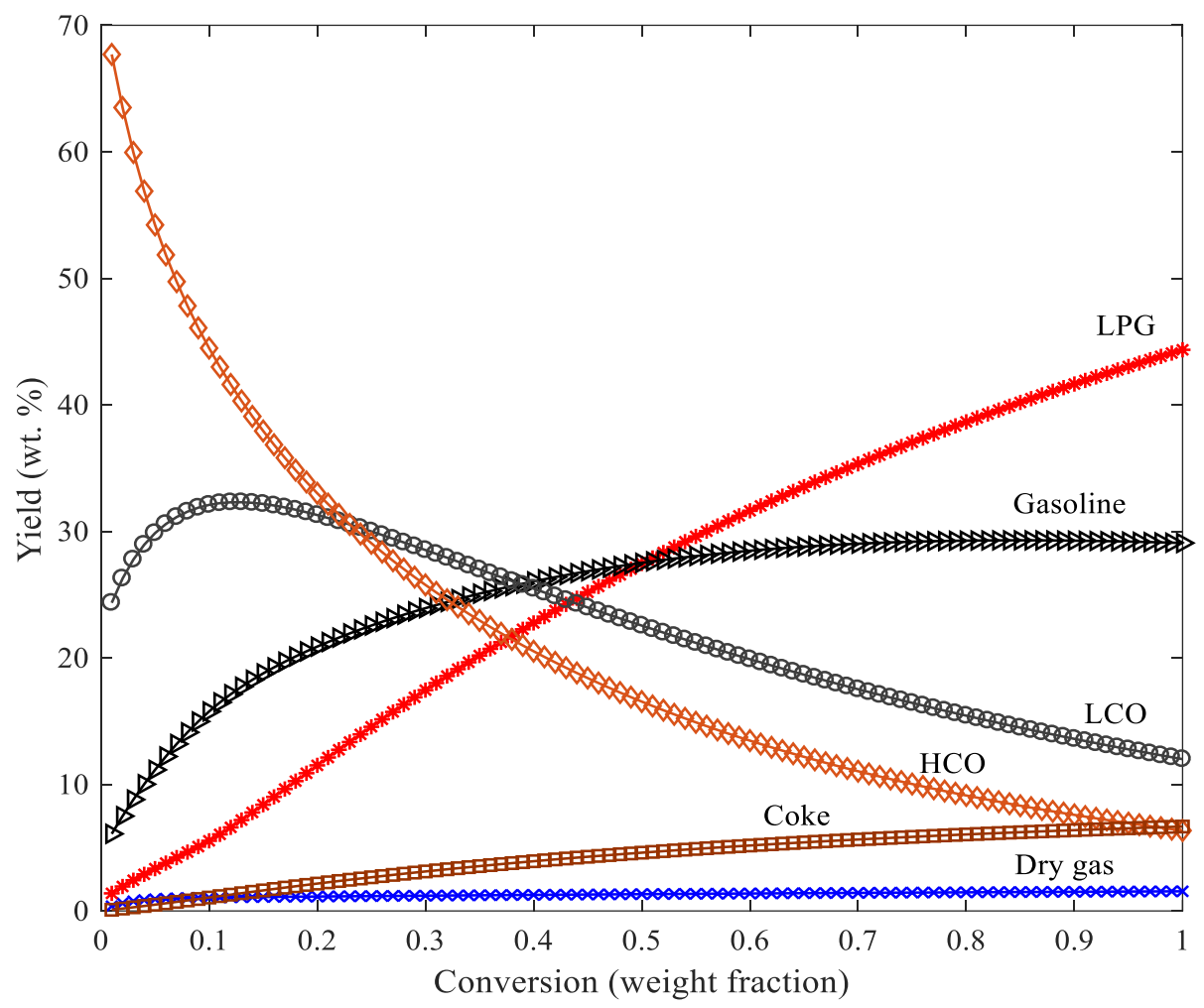

Figure 8 Individual product yield with conversion

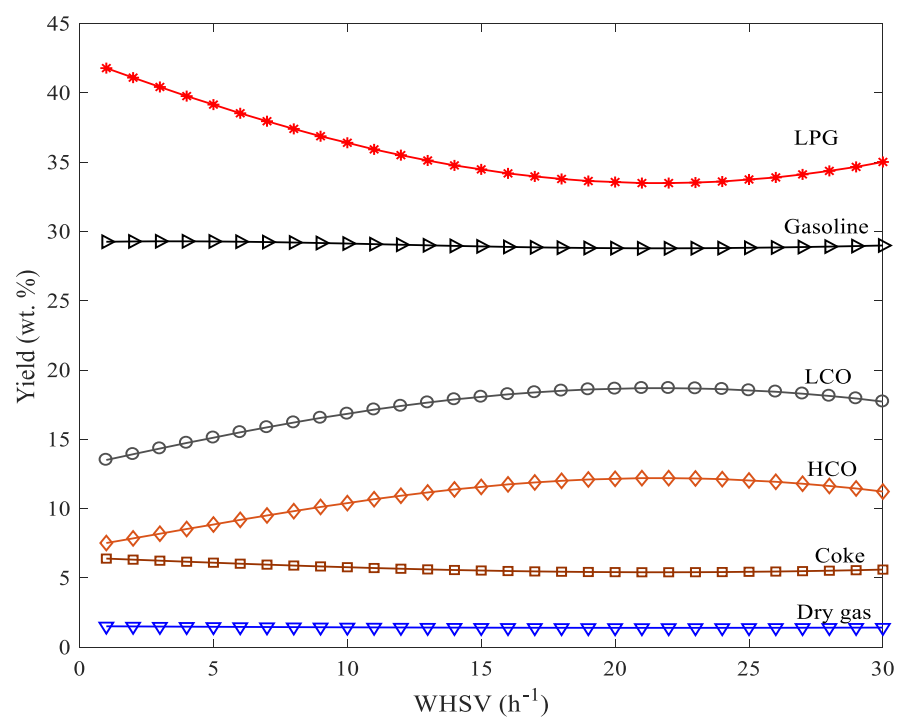


Figure 9 Individual product yield with WHSV
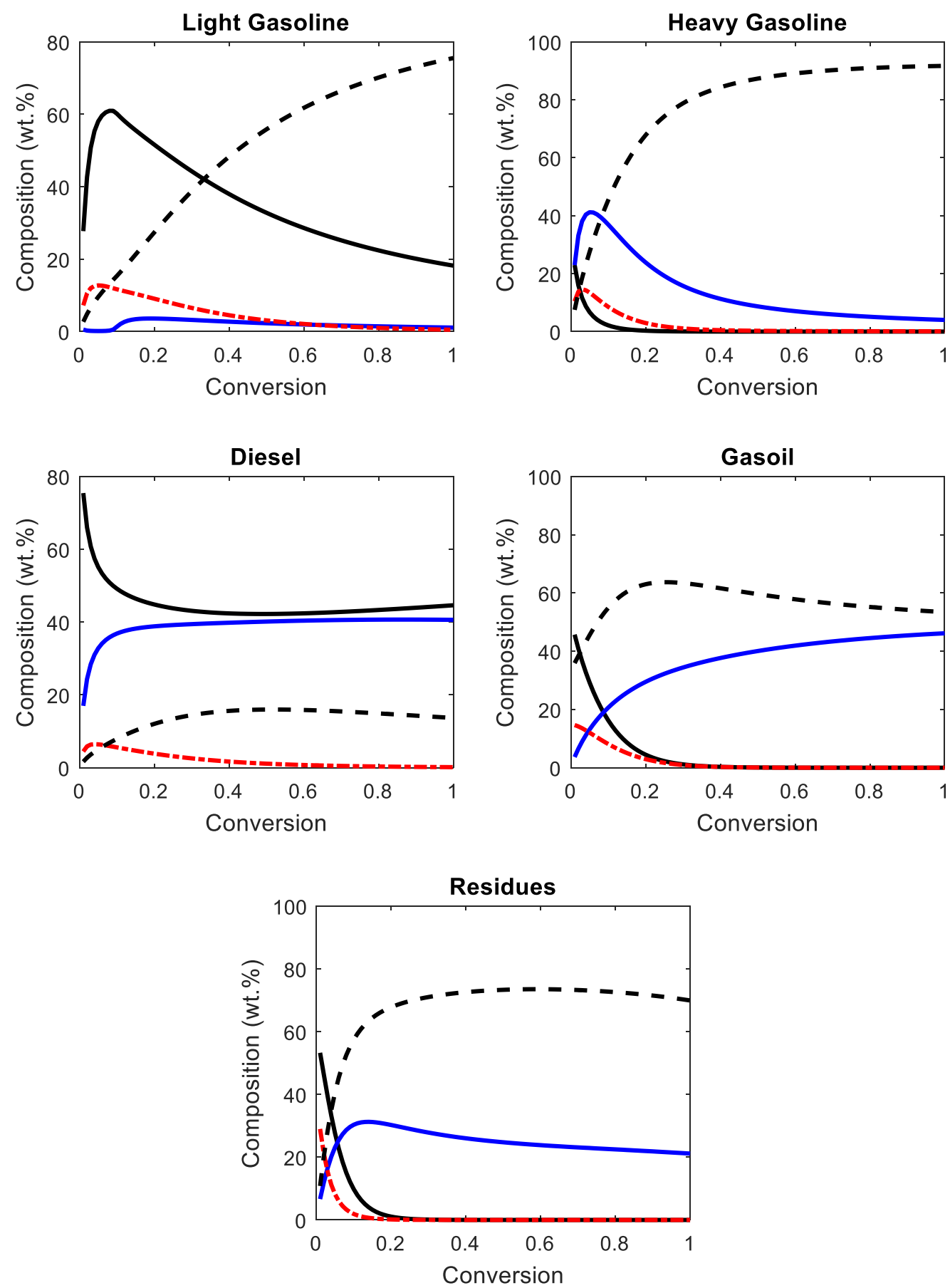

$\longrightarrow \mathrm{P}=\mathrm{O}-=-\mathrm{N}-\mathrm{A}$

Figure 10 PONA composition in liquid products with different conversion rates

Table 8 illustrates the compositions of aromatics and olefins in the heavy gasoline product. Their compositions in the same product with VGO feed only are also given in Table 
8. From Table 8, it can be observed that the composition of aromatics in the heavy gasoline is larger than in conventional FCC gasoline. This result goes in line with the results obtained by de Rezende Pinho et al. ${ }^{17}$ in which the composition of aromatics in gasoline product is higher when bio oil is co-processed in FCC unit compared to pure VGO processing. The main possible reason is expected to be that FPO is a hydrogen-deficient liquid and more hydrogen in VGO is consumed to saturate the unsaturated bonds in FPO when coprocessing. However, the composition of olefins decreases by 19 wt. \% approximately in co-processing experiments. It should be noted that the large differences shown in Table 8 in the values of olefins and aromatics composition is because of the large differences in petroleum and bio oil feedstocks.

Table 8 Aromatics and olefins compositions in the gasoline product

\begin{tabular}{|l|l|l|l|}
\hline & $0 \%$ bio-oil $^{17}$ & $20 \%$ bio-oil $^{17}$ & $5 \%$ boil-oil (This work) \\
\hline & HCN & HCN & Heavy gasoline \\
\hline Conversion (wt.\%) & 80 & 80 & 80 \\
\hline Olefins (wt.\%) & 28.8 & 24.5 & 5.05 \\
\hline Aromatics (wt.\%) & 50 & 53.8 & 90.97 \\
\hline
\end{tabular}

\subsection{Oxygenates Composition in Products}

It is highly desirable to monitor the composition of oxygenates in transportation fuels because of recent regulations on oxygenates content. Table 9 shows oxygenates requirements for gasoline in the EU. ${ }^{65}$ Table 10 shows oxygen and oxygenates content in the gasoline product from the FCC unit where oxygen content can be calculated based on average values of oxygen content in each of the oxygenated groups. The predicted composition of oxygenates groups (i.e., Phenolics, Aldehydes and ketones, Acids and esters, and alcohols) in each product from the FCC unit is illustrated in Figure 11. From Figure 11, it can be observed that as WHSV increases (C/O decreases), the total yield of phenolics oxygenates group increases 
first until it reaches a maximum and then decreases. This goes in line with the findings of Thegarid et al. ${ }^{66}$ in which the total composition of phenols and alkyl phenols increases with smaller $\mathrm{C} / \mathrm{O}$ ratio until a maximum value is reached, and then starts to decrease when the value of $\mathrm{C} / \mathrm{O}$ ratio drops below $3(\mathrm{~g} / \mathrm{g})$. Similar behaviour for aldehydes and ketones oxygenates group is noticed. This likely stems from the fact that as $\mathrm{C} / \mathrm{O}$ decreases, the total conversion of phenolics in the gasoline cut increases, due to the low crackability of phenolics cuts compared to the other types of molecules in the gasoline cut. However, as the $\mathrm{C} / \mathrm{O}$ drops below a certain value, the total conversion of phenolics from heavier cuts starts to decrease, resulting in a lower yield of phenolics in the gasoline cut.

Table 9 Oxygenates requirements for transportation gasoline in the $\mathrm{EU}^{65}$

\begin{tabular}{lll}
\hline Item & Unit & $\begin{array}{l}\text { Maximum } \\
\text { Limit }\end{array}$ \\
\hline Oxygen content & $\% \mathrm{~m} / \mathrm{m}$ & 3.7 \\
Methanol & $\% \mathrm{v} / \mathrm{v}$ & 3 \\
Ethanol (stabilising agents may be necessary) & $\% \mathrm{v} / \mathrm{v}$ & 10 \\
Iso-propyl alcohol & $\% \mathrm{v} / \mathrm{v}$ & 12 \\
Tert-butyl alcohol & $\% \mathrm{v} / \mathrm{v}$ & 15 \\
Iso-butyl alcohol & $\% \mathrm{v} / \mathrm{v}$ & 15 \\
Ethers containing five or more carbon atoms per molecule & $\% \mathrm{v} / \mathrm{v}$ & 22 \\
Other oxygenates & $\% \mathrm{v} / \mathrm{v}$ & 15 \\
\hline
\end{tabular}

Table 10 Oxygen and oxygenates content in the gasoline product from the FCC unit

\begin{tabular}{lll}
\hline Parameter & Unit & Model Value \\
\hline WHSV & $\mathrm{h}^{-1}$ & 15 \\
Oxygen content & $\% \mathrm{~m} / \mathrm{m}$ & 0.175 \\
Phenolics & $\% \mathrm{v} / \mathrm{v}$ & 2.60 \\
Acids and esters & $\% \mathrm{v} / \mathrm{v}$ & $9.03 \mathrm{E}-08$
\end{tabular}


Alcohols

Aldehydes and ketones
$\% \mathrm{v} / \mathrm{v}$

$\% \mathrm{v} / \mathrm{v}$

2.03

\section{Note: $\mathrm{WHSV}=15 \mathrm{~h}^{-1}$}
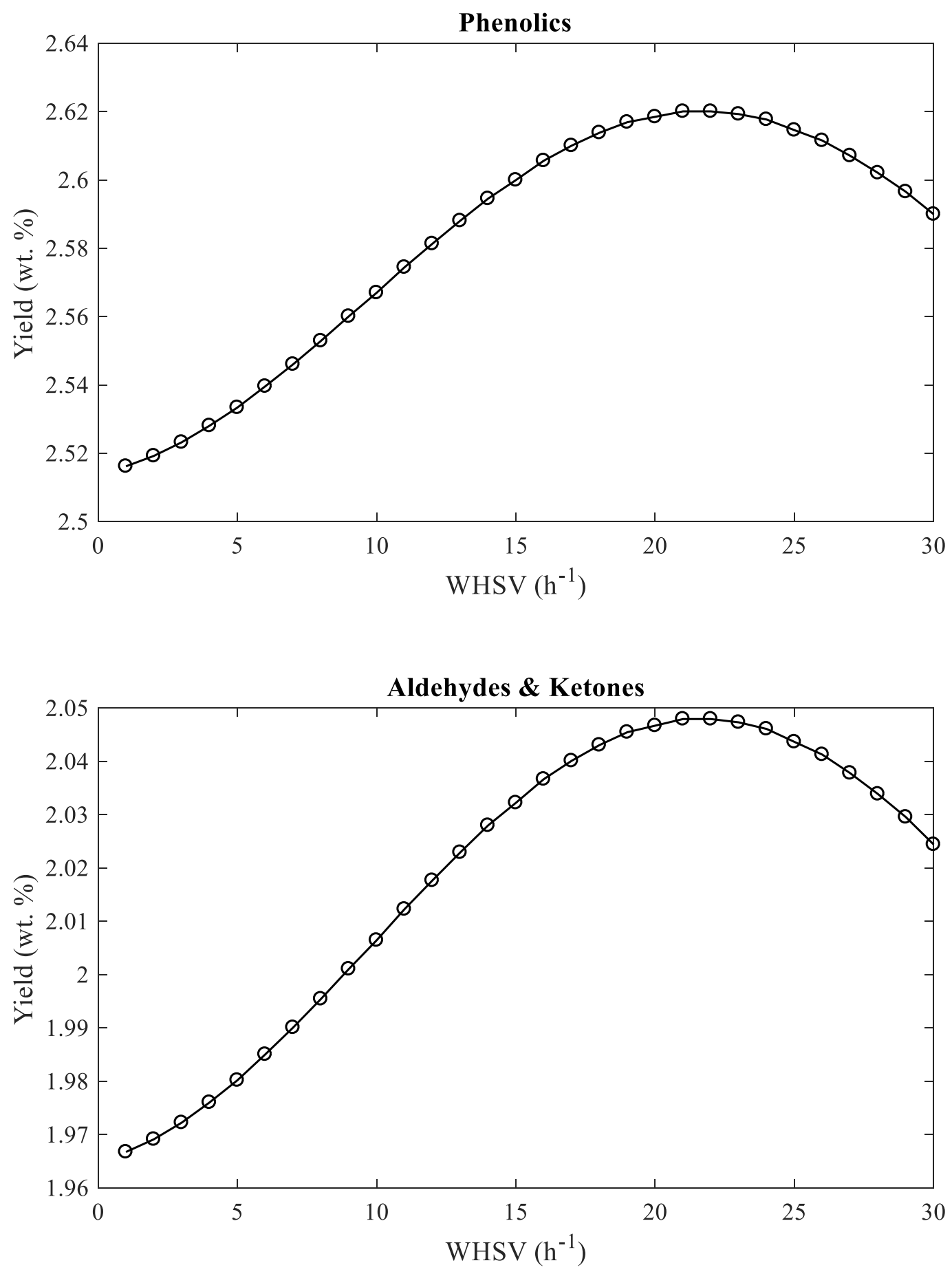

Figure 11 Yields of phenolics, aldehydes and ketones in gasoline cut as a function of WHSV

From Figure 11 and Table 10, it can be concluded that the values obtained from the model show that blending $5 \mathrm{wt} \% \%$ of FPO with $95 \mathrm{wt} . \%$ of VGO as the feed to the FCC unit 
could produce gasoline range product with oxygen and oxygenates content that is well below the maximum allowable limit. This also means that co-processing FPO with VGO with that ratio (5:95) in the FCC unit does not affect downstream oxygenates finishing/blending window significantly.

\subsection{Sensitivity Analysis}

FCC reactor operating conditions such as the operating temperature can be adjusted to maximise the yield of desired products. It is often required to maximise gasoline yield to increase refinery profit margin ${ }^{58-62}$. The effect of reaction temperature on the yield of different products and oxygen content is investigated through sensitivity analysis using the developed kinetic model. Reaction temperature is varied from $470^{\circ} \mathrm{C}$ to $550^{\circ} \mathrm{C}$. The effect of reaction temperature on product yields is illustrated in Figure 12. 

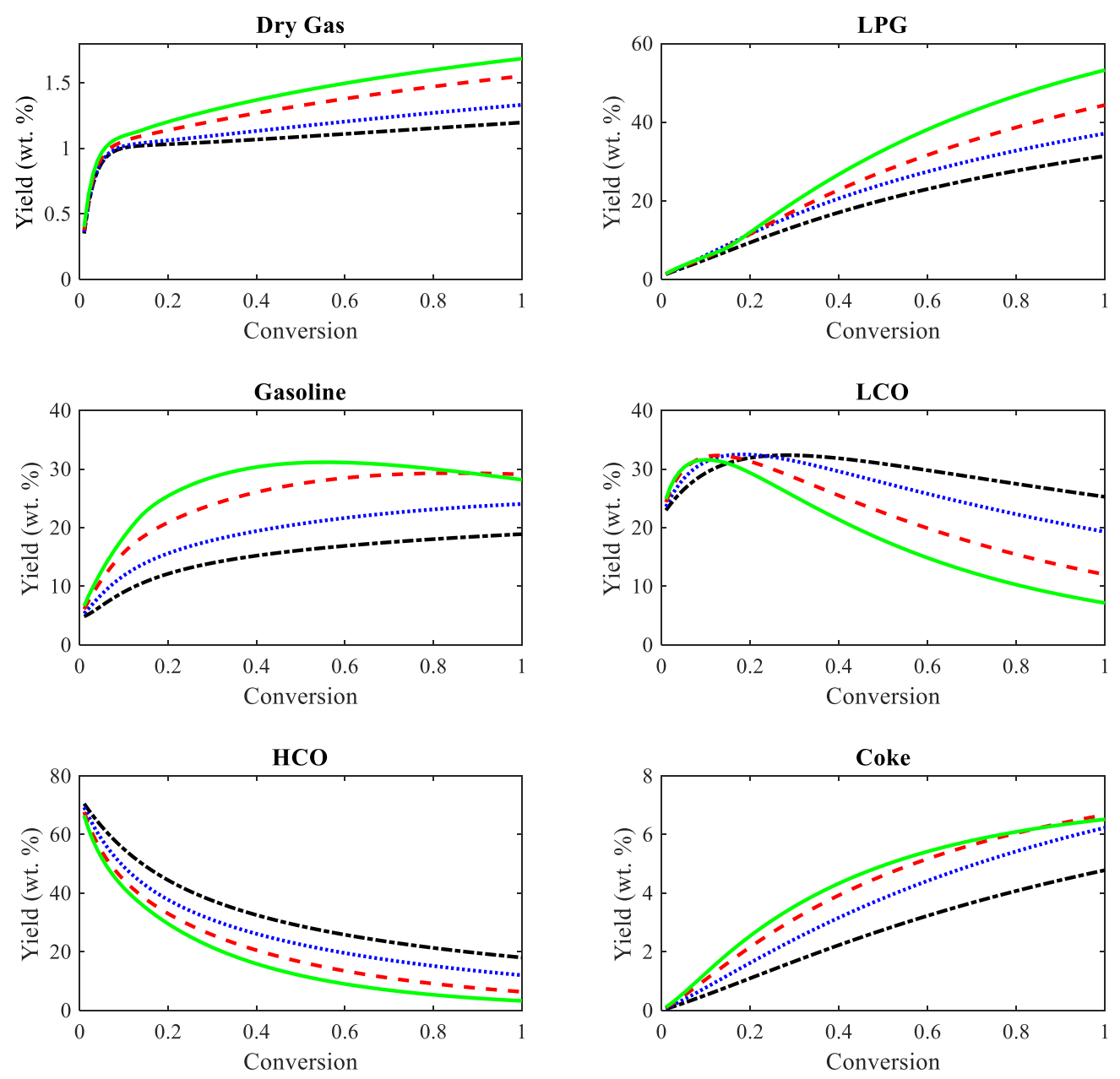

$---470^{\circ} \mathrm{C} \cdots \cdots \cdot \cdots \cdot 500^{\circ} \mathrm{C}--530^{\circ} \mathrm{C}=550^{\circ} \mathrm{C}$

Figure 12 Variation of product yields with conversion for different temperatures

As seen from Figure 12, it is generally noted that as the reaction temperature increases, yields of cracking products (i.e., dry gas, LPG, and gasoline) increase, while yields of diesel, gasoil, and residue (LCO and HCO) decreases. This is believed to be due to the increase of cracking reaction rates with increasing reaction temperature. It can also be seen from Figure 12 that as reaction temperature increases from $530^{\circ} \mathrm{C}$ to $550^{\circ} \mathrm{C}$, the yield of gasoline product starts dropping beyond 0.8 conversion value. This can be justified by the fact that at reaction temperature of $550^{\circ} \mathrm{C}$, reactor operation enters gasoline over-cracking region beyond conversion value of 0.8 .

Figure 13 shows the effect of reaction temperature on oxygen content in various 
products as a function of conversion. It can clearly be seen that as reaction temperature increases, oxygen content increases in diesel, gasoil and residues cuts, whereas it decreases in in light gasoline cut. This is mainly due to the fact that as reaction temperature increases, the cracking rate of all structural lumps within heavy cuts (diesel, gasoil, and residues) increases, which leads to general decreases in the total yield of that lump. However, cracking rates of oxygenates do not increase as much as hydrocarbon lumps. This in turn leads to an increase in oxygenates composition in the lump (Figure 14), hence oxygen content. For gasoline cuts, as reaction temperature increases, the total yield of light gasoline always increases. This results in general decrease in oxygenates yields within the cut, hence oxygen content. In terms of heavy gasoline, oxygen content within this product lump shows a minimum at reaction temperature of $550^{\circ} \mathrm{C}$ and conversion value of 0.5 , after which the oxygen content starts to increase again. This behaviour is believed to be due to entering gasoline overcracking region beyond reaction temperature of $530^{\circ} \mathrm{C}$ and conversion value of 0.5 . Gasoline over-cracking leads to decrease in total yield of heavy gasoline, and therefore, oxygenates yields increases, hence oxygen content within the lump. 

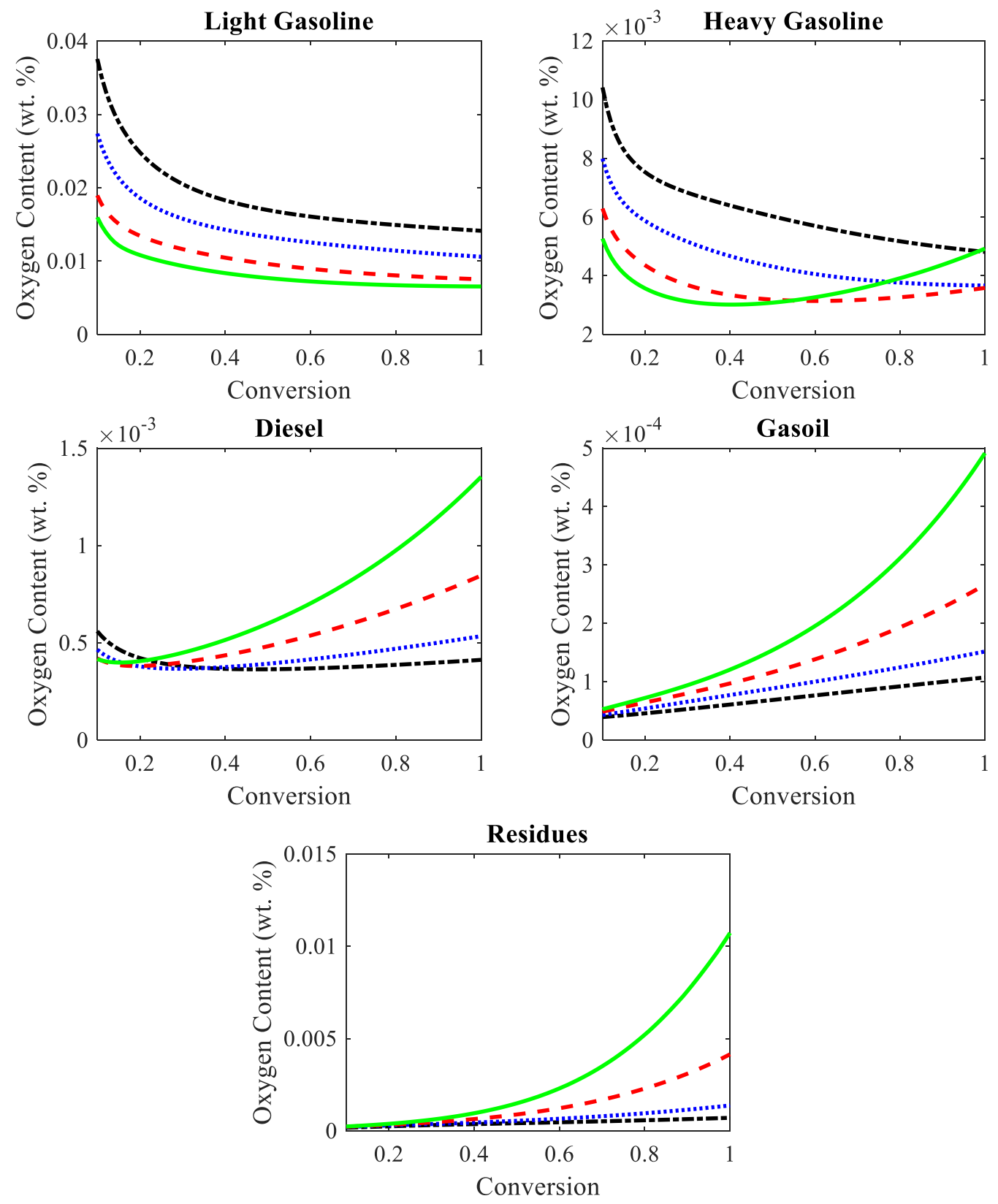

$$
\text { -- } 470^{\circ} \mathrm{C} \cdots \cdots \cdot \ldots 500^{\circ} \mathrm{C}=-530^{\circ} \mathrm{C}-550^{\circ} \mathrm{C}
$$

Figure 13 Variation of oxygen content within liquid products with conversion for different reaction temperatures 


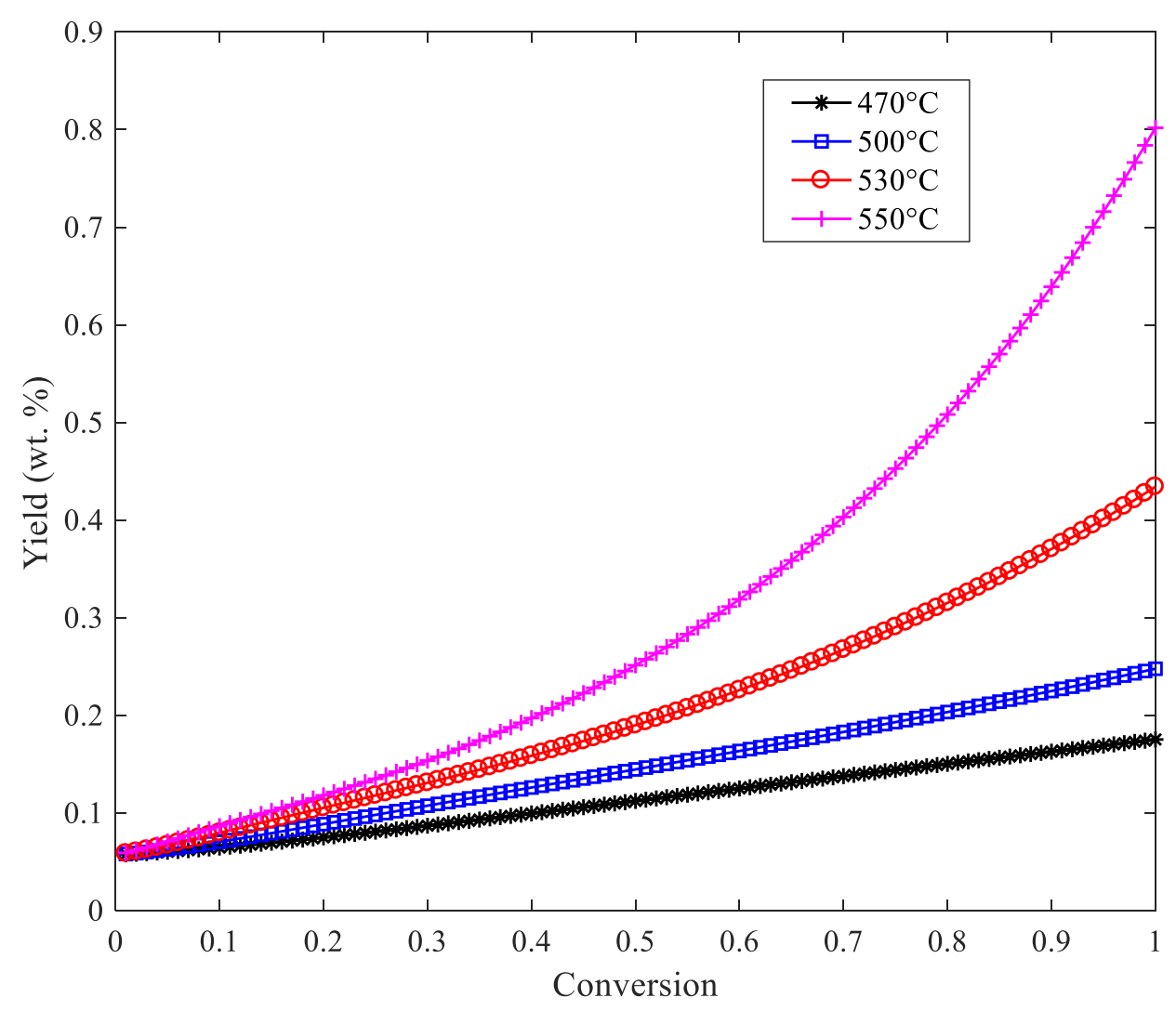

Figure 14 Variation of Phenols yields in gas oil cut with conversion for different temperatures

\section{Conclusions}

In this paper, a novel framework for molecular-level modelling of co-processing biomass pyrolysis with VGO in an oil refinery FCC unit was proposed. The framework incorporated a molecular-level characterisation method based on the MTHS matrix approach proposed in Al Jamri et al. $^{2}$ and a molecular-level reaction network to provide detailed, molecular-level description of feed and product streams. A novel catalytic cracking reaction model was developed, which comprises 328 reactions used to describe the behaviour of 58 lumps in catalytic cracking reactor. The concept of reaction family was employed to reduce parameters in the catalytic cracking reaction model to 12 only. An NLP parameter estimation problem was set up to estimate the kinetic parameters, which was solved using the proposed hybrid solution algorithm with the combination of stochastic (GA) and deterministic (SQP) 
algorithms. The computational results demonstrate good agreement between the experimental data and model-predicted values. Sensitivity analysis was performed to investigate the effect of reactor temperature on product distribution and oxygen content in each product cut. Results of sensitivity analysis showed that cracking rates increase with increasing reaction temperature resulting in a larger light product yield. In addition, increasing reaction temperature had different effects on cracking rates on oxygenates compared to hydrocarbons. The results of sensitivity analysis showed that the increase in the rates of oxygenates cracking reactions is much less compared to hydrocarbons cracking reactions.

It can also be concluded that the proposed modelling framework is capable of providing detailed, molecular-level description of both feed and product streams, while maintaining a manageable size for both characterisation and reaction network. PONA and oxygenates composition, as well as oxygen content in each product cut (e.g. gasoline, diesel, etc.) are predicted, which creates potentials for rigorous optimisation of process parameters for refinery profit maximisation or better products' quality control. The framework developed in this work can easily be extended to modelling of other refinery processes. 


\section{ASSOCIATED CONTENT}

\section{Supporting Information}

- Reaction network for co-processing biomass pyrolysis oil in catalytic cracking unit.

- Values of kinetic parameters prior and post kinetic parameters regression problem.

\section{AUTHOR INFORMATION}

\section{Corresponding Author}

*E-mail: jie.li-2@manchester.ac.uk.

\section{Author Contributions}

The manuscript was written through contributions of all authors. All authors have given approval to the final version of the manuscript.

\section{Funding Sources}

The authors would like to acknowledge the financial support from Research Impact Scholarship, The University of Manchester, United Kingdom.

\section{Notes}

The authors declare no competing financial interest.

\section{ACKNOWLEDGEMENT}

The Authors would like to acknowledge the financial support from Research Impact Scholarship, The University of Manchester, United Kingdom. 


\section{REFERENCES}

1. $\quad$ Agency, I. E., World Energy Outlook 2013. 2013.

2. Al Jamri, M.; Smith, R.; Li, J., Molecular Characterisation of Biomass Pyrolysis Oil and Petroleum Fraction Blends. Computers \& Chemical Engineering 2019.

3. Elliott, D. C., Transportation fuels from biomass via fast pyrolysis and hydroprocessing. Wiley Interdisciplinary Reviews: Energy and Environment 2013, 2, $525-$ 533.

4. Huber, W.; Avelino, C., Synergies between Bio- and Oil Refineries for the Production of Fuels from Biomass. Angewandte Chemie International Edition 2007, 46, 7184-7201.

5. Jones, S.; Meyer, P.; Snowden-swan, L.; Tan, E.; Dutta, A.; Jacobson, J.; Cafferty, K., Process Design and Economics for the Conversion of Lignocellulosic Biomass to Hydrocarbon Fuels Fast Pyrolysis and Hydrotreating. PNNL Report 2013, PNNL-23053, 97.

6. Su-Ping, Z., Study of Hydrodeoxygenation of Bio-Oil from the Fast Pyrolysis of Biomass. Energy Sources 2003, 25, 57-65.

7. Al-Sabawi, M.; Chen, J.; Ng, S., Fluid Catalytic Cracking of Biomass-Derived Oils and Their Blends with Petroleum Feedstocks: A Review. Energy \& Fuels 2012, 26, $5355-$ 5372 .

8. de Rezende Pinho, A.; de Almeida, M. B. B.; Mendes, F. L.; Casavechia, L. C.; Talmadge, M. S.; Kinchin, C. M.; Chum, H. L., Fast pyrolysis oil from pinewood chips coprocessing with vacuum gas oil in an FCC unit for second generation fuel production. Fuel 2017, 188, 462-473.

9. Fogassy, G.; Thegarid, N.; Toussaint, G.; van Veen, A. C.; Schuurman, Y.; Mirodatos, C., Biomass derived feedstock co-processing with vacuum gas oil for secondgeneration fuel production in FCC units. Applied Catalysis B: Environmental 2010, 96, 476485 .

10. Gueudré, L.; Chapon, F.; Mirodatos, C.; Schuurman, Y.; Venderbosch, R.; Jordan, E.; Wellach, S.; Gutierrez, R. M., Optimizing the bio-gasoline quantity and quality in fluid catalytic cracking co-refining. Fuel 2017, 192, 60-70.

11. Wang, C.; Li, M.; Fang, Y., Coprocessing of Catalytic-Pyrolysis-Derived Bio-Oil with VGO in a Pilot-Scale FCC Riser. Industrial \& Engineering Chemistry Research 2016, $55,3525-3534$.

12. Naik, D. V.; Karthik, V.; Kumar, V.; Prasad, B.; Garg, M. O., Kinetic modeling for catalytic cracking of pyrolysis oils with VGO in a FCC unit. Chemical Engineering Science 2017, 170, 790-798.

13. Agblevor, F. A.; Mante, O.; McClung, R.; Oyama, S. T., Co-processing of standard gas oil and biocrude oil to hydrocarbon fuels. Biomass and Bioenergy 2012, 45, 130-137.

14. Naik, D. V.; Kumar, V.; Prasad, B.; Poddar, M. K.; Behera, B.; Bal, R.; Khatri, O. P.; Adhikari, D. K.; Garg, M. O., Catalytic cracking of jatropha-derived fast pyrolysis oils with VGO and their NMR characterization. RSC Adv. 2015, 5, 398-409.

15. de Miguel Mercader, F.; Groeneveld, M. J.; Kersten, S. R. A.; Geantet, C.; Toussaint, G.; Way, N. W. J.; Schaverien, C. J.; Hogendoorn, K. J. A., Hydrodeoxygenation of pyrolysis oil fractions: process understanding and quality assessment through co-processing in refinery units. Energy Environ. Sci. 2011, 4, 985-997.

16. de Miguel Mercader, F.; Groeneveld, M. J.; Kersten, S. R. A.; Way, N. W. J.; Schaverien, C. J.; Hogendoorn, J. A., Production of advanced biofuels: Co-processing of upgraded pyrolysis oil in standard refinery units. Applied Catalysis B: Environmental 2010, 96, 57-66. 
17. de Rezende Pinho, A.; de Almeida, M. B. B.; Mendes, F. L.; Ximenes, V. L.; Casavechia, L. C., Co-processing raw bio-oil and gasoil in an FCC Unit. Fuel Processing Technology 2015, 131, 159-166.

18. Fogassy, G.; Thegarid, N.; Schuurman, Y.; Mirodatos, C., From biomass to biogasoline by FCC co-processing: effect of feed composition and catalyst structure on product quality. Energy Environ. Sci. 2011, 4, 5068-5076.

19. Naik, D. V.; Kumar, V.; Prasad, B.; Behera, B.; Atheya, N.; Adhikari, D. K.; Nigam, K. D. P.; Garg, M. O., Catalytic Cracking of C2-C3 Carbonyls with Vacuum Gas Oil. Industrial \& Engineering Chemistry Research 2014, 53, 18816-18823.

20. Gomez-Prado, J. Integrated Methodology for the Modelling of Refinery Fluid Catalytic Cracking Units. University of Manchester, Manchester, 2009.

21. Xu, C.; Gao, J.; Zhao, S.; Lin, S., Correlation between feedstock SARA components and FCC product yields. Fuel 2005, 84, 669-674.

22. Feng, W.; Vynckier, E.; Froment, G. F., Single event kinetics of catalytic cracking. Industrial \& Engineering Chemistry Research 1993, 32, 2997-3005.

23. Blanding, F. H., Reaction Rates in Catalytic Cracking of Petroleum. Industrial \& Engineering Chemistry 1953, 45, 1186-1197.

24. Weekman, W.; Nace, M., Kinetics of catalytic cracking selectivity in fixed, moving, and fluid bed reactors. AIChE Journal 1970, 16, 397-404.

25. Gomez-Prado, J. Modelling of Refinery Fluid Catalytic Cracking Units

UMIST, Manchester, 2003.

26. $\mathrm{Hu}, \mathrm{S}$.; Towler, G.; Zhu, X. X., Combine Molecular Modeling with Optimization to Stretch Refinery Operation. Industrial engineering chemistry research 2002, 41, (4), 825841.

27. Zhu, F. X. X., Molecular Analysis for Process Synthesis. Industrial \& Engineering Chemistry Research 2018, 57, (43), 14583-14595.

28. Cruz, P. L.; Montero, E.; Dufour, J., Modelling of co-processing of HDO-oil with VGO in a FCC unit. Fuel 2017, 196, 362-370.

29. Araujo-Monroy, C.; López-Isunza, F., Modeling and Simulation of an Industrial Fluid Catalytic Cracking Riser Reactor Using a Lump-Kinetic Model for a Distinct Feedstock. Industrial \& Engineering Chemistry Research 2006, 45, 120-128.

30. Jacob, S. M.; Gross, B.; Voltz, S. E.; Weekman, V. W., A lumping and reaction scheme for catalytic cracking. AIChE Journal 1976, 22, 701-713.

31. Watson, B.; Klein, M. T.; Harding, R. H., Mechanistic Modeling of n-Heptane Cracking on HZSM-5. Industrial \& Engineering Chemistry Research 1996, 35, 1506-1516.

32. Watson, B.; Klein, M. T.; Harding, R. H., Mechanistic Modeling of n-Hexadecane Cracking on Rare Earth Y. Energy \& Fuels 1997, 11, 354-363.

33. Watson, B.; Klein, M. T.; Harding, R. H., Mechanistic Modeling of a 1Phenyloctane/n-Hexadecane Mixture on Rare Earth Y Zeolite. Industrial \& Engineering Chemistry Research 1997, 36, 2954-2963.

34. Watson, B.; Klein, M. T.; Harding, R. H., Catalytic cracking of alkylbenzenes: Modeling the reaction pathways and mechanisms. Applied Catalysis A: General 1997, 160, 13-39.

35. Watson, B. A.; Klein, M. T.; Harding, R. H., Catalytic cracking of alkylcyclohexanes: Modeling the reaction pathways and mechanisms. Int. J. Chem. Kinet. 1997, 29, 545-560.

36. Gates, B., Chemistry of Catalytic Processes. 1979.

37. Adjaye, J. D.; Bakhshi, N. N., Catalytic conversion of a biomass-derived oil to fuels and chemicals II: Chemical kinetics, parameter estimation and model predictions. Biomass and Bioenergy 1995, 8, 265-277. 
38. Adjaye, J. D.; Bakhshi, N. N., Catalytic conversion of a biomass-derived oil to fuels and chemicals I: Model compound studies and reaction pathways. Biomass and Bioenergy 1995, 8, 131-149.

39. Adjaye, J. D.; Bakhshi, N. N., Production of hydrocarbons by catalytic upgrading of a fast pyrolysis bio-oil. Part II: Comparative catalyst performance and reaction pathways. Fuel Processing Technology 1995, 45, 185-202.

40. Chen, N. Y.; Garwood, W. E.; Dwyer, F. G., Shape Selective Catalysis in Industrial Applications. 1996.

41. Kwart, H.; King, K., The Chemistry of Carboxylic Acids and Esters. 1969.

42. Graça, I.; Lopes, J. M.; Ribeiro, M. F.; Ribeiro, F. R.; Cerqueira, H. S.; de Almeida, M. B. B., Catalytic cracking in the presence of guaiacol. Applied Catalysis B: Environmental 2011, 101, 613-621.

43. Naik, D. V.; Kumar, V.; Prasad, B.; Behera, B.; Atheya, N.; Singh, K. K.; Adhikari, D. K.; Garg, M. O., Catalytic cracking of pyrolysis oil oxygenates (aliphatic and aromatic) with vacuum gas oil and their characterization. Chemical Engineering Research and Design 2014, 92, 1579-1590.

44. Renavd, M.; Chantal, D.; Kaliaguine, S., Anisole production by alkylation of phenol over ZSM5. The Canadian Journal of Chemical Engineering 1986, 64, 787-791.

45. Ahmad, M. I.; Zhang, N.; Jobson, M., Integrated design of diesel hydrotreating processes. Chemical Engineering Research and Design 2011, 89, 1025-1036.

46. Sun, J., Molecular Modelling and Integration Analysis of Hydroprocessors. In 2004.

47. Pitault, I.; Nevicato, D.; Forissier, M.; Bernard, J.-R., Kinetic model based on a molecular description for catalytic cracking of vacuum gas oil. Chemical Engineering Science 1994, 49, 4249-4262.

48. Kambreck, F., The Mobil Workshop. In Continuous Mixtures in Fluid Catalytic Cracking and Extensions, Van Nostrad Reinhold: New York, 1991.

49. Kumar, P.; Kunzru, D., Kinetics of coke deposition in naphtha pyrolysis. The Canadian Journal of Chemical Engineering 1985, 63, 598-604.

50. Biegler, L.; Grossmann, I.; Westerberg, A., Systematic Methods Of Chemical Process Design. Upper Saddle River, NJ: Prentice Hall PTR 1997.

51. Duran, M. A.; Grossmann, I. E., An outer-approximation algorithm for a class of mixed-integer nonlinear programs. Mathematical Programming 1986, 36, 307-339.

52. $\quad$ Edgar, T. F.; Himmelblau, D. M.; Lasdon, L. S., Optimisation of Chemical Processes. 2001.

53. Floudas, C. A., Deterministic Global Optimization: Theory, Methods and Applications. 2013.

54. Heyman, D. P.; Sobel, M. J., Stochastic Models in Operations Research: Stochastic optimization. 2003.

55. Hidalgo-Vivas, A., Reactive Distillation for Middle Distilates Hydrotreatment. In 1999.

56. Bekirogullari, M.; Fragkopoulos, I. S.; Pittman, J. K.; Theodoropoulos, C., Production of lipid-based fuels and chemicals from microalgae: An integrated experimental and modelbased optimization study. Algal Research 2017, 23, 78-87.

57. Figueroa-Torres, G. M.; Pittman, J. K.; Theodoropoulos, C., Kinetic modelling of starch and lipid formation during mixotrophic, nutrient-limited microalgal growth. Bioresource Technology 2017, 241, 868-878.

58. Ancheyta-Juárez, J.; López-Isunza, F.; Aguilar-Rodríguez, E.; Moreno-Mayorga, J. C., A Strategy for Kinetic Parameter Estimation in the Fluid Catalytic Cracking Process. Industrial \& Engineering Chemistry Research 1997, 36, 5170-5174. 
59. Ancheyta-Juárez, J.; Murillo-Hernández, J. A., A Simple Method for Estimating Gasoline, Gas, and Coke Yields in FCC Processes. Energy \& Fuels 2000, 14, 373-379.

60. Ancheyta-Juárez, J.; Sotelo-Boyás, R., Estimation of Kinetic Constants of a FiveLump Model for Fluid Catalytic Cracking Process Using Simpler Sub-models. Energy \& Fuels 2000, 14, 1226-1231.

61. Mota, C. J. A.; Rawet, R., Mechanism of Aromatic Hydrocarbon Formation in FCC Naphtha. Industrial \& Engineering Chemistry Research 1995, 34, 4326-4332.

62. Wallenstein, D.; Alkemade, U., Modelling of selectivity data obtained from microactivity testing of FCC catalysts. Applied Catalysis A: General 1996, 137, 37-54.

63. Mi Saine Aye, M.; Zhang, N., A novel methodology in transforming bulk properties of refining streams into molecular information. Chemical Engineering Science 2005, 60, $6702-6717$.

64. Wu, Y.; Zhang, N., Molecular Characterization of Gasoline and Diesel Streams. Industrial \& Engineering Chemistry Research 2010, 49, 12773-12782.

65. European, U. EU: FUELS: DIESEL AND GASOLINE. https://www.transportpolicy.net/standard/eu-fuels-diesel-and-gasoline/ (01-06-2018),

66. Thegarid, N.; Fogassy, G.; Schuurman, Y.; Mirodatos, C.; Stefanidis, S.; Iliopoulou, E. F.; Kalogiannis, K.; Lappas, A. A., Second-generation biofuels by co-processing catalytic pyrolysis oil in FCC units. Applied Catalysis B: Environmental 2014, 145, 161-166. 
For Table of Contents Only

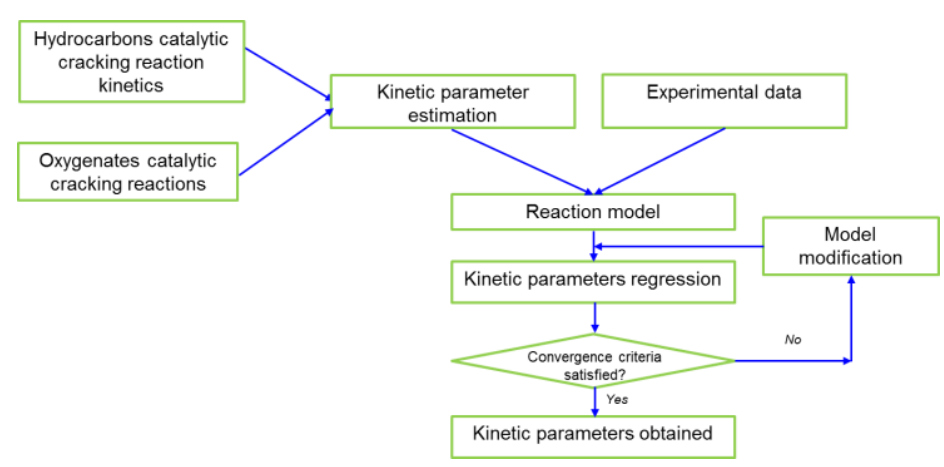

